\title{
Epidemiologic Trends, Global Shifts in Meningococcal Vaccination Guidelines, and Data Supporting the Use of MenACWY-TT Vaccine: A Review
}

\author{
Jessica Presa · Jamie Findlow · Jelena Vojicic · Scott Williams •
}

Lidia Serra

Received: April 30, 2019 / Published online: July 25, 2019

(C) The Author(s) 2019

\begin{abstract}
Neisseria meningitidis is a major cause of meningitis and septicemia with cases, outbreaks, and epidemics reported globally in industrialized and non-industrialized countries. $N$. meningitidis is categorized into 12 serogroups; however, only 5 serogroups (A, B, C, $\mathrm{W}, \mathrm{Y})$ are responsible for the majority of disease. Invasive meningococcal disease (IMD) occurs unpredictably; protection is therefore best achieved by initiating proactive vaccination strategies. Vaccines are currently available for the five main disease-causing serogroups. With the evolution of meningococcal vaccines and changes in IMD epidemiology, different
\end{abstract}

Enhanced digital features To view enhanced digital features for this article go to https://doi.org/10.6084/ m9.figshare.8792150.

J. Presa · L. Serra $(\bowtie)$

Global Medical Development and Scientific/Clinical Affairs, Pfizer Inc, Collegeville, PA, USA

e-mail: Lidia.Oliveira@Pfizer.com

J. Findlow

Medical and Scientific Affairs, International

Developed Markets, Pfizer Ltd, Tadworth, Surrey, UK

J. Vojicic

Pfizer Canada ULC, Kirkland, QC, Canada

S. Williams

Pfizer Australia, Sydney, NSW, Australia vaccination strategies have been used. Recently, the rapid clonal expansion of meningococcal serogroup $\mathrm{W}$ (MenW) has been associated with a change in the national and regional vaccination recommendations from monovalent meningococcal serogroup $C$ vaccines to meningococcal serogroup A, C, W, Y (MenACWY) vaccines in several countries. This review highlights these and other changes in IMD epidemiology and meningococcal vaccination recommendations, summarizes information available for currently available conjugate MenACWY vaccines, and focuses on clinical study data for the most recently approved MenACWY conjugate vaccine, MenACWY vaccine conjugated to tetanus toxoid (MenACWY-TT). MenACWY-TT studies spanned multiple age groups and generally demonstrated safety and immunogenicity in comparison with other meningococcal vaccines and under concomitant administration of other routine vaccines. Continuous updates to meningococcal vaccine recommendations in response to changing epidemiology, as have been undertaken for MenW, are necessary to ensure optimal population protection.

Funding: Pfizer, Inc.

Keywords: Epidemiologic monitoring; Immunization programs; Immunogenicity; Meningococcal infections; Meningococcal vaccines; Vaccine 


\section{INTRODUCTION}

Invasive meningococcal disease (IMD) is a serious infection caused by the Gram-negative bacterium Neisseria meningitidis [1]. Some age groups are disproportionately affected by IMD, with major peaks of IMD incidence occurring in infants and in adolescents and young adults [2-4]. Adolescents and young adults typically exhibit lifestyles that are thought to promote meningococcal transmission, such as being exposed to smoke; frequent attendance at pubs, bars, and nightclubs; living in close quarters; and intimate kissing with multiple partners $[5,6]$. IMD rates are markedly elevated among students in universities relative to other settings $[2,7]$, and outbreaks or clusters of disease within the university setting can occur [8-10]. Overall incidence of IMD is generally low but varies by country/region [2, 3]. Nevertheless, outbreaks are unpredictable [11], and sporadic individual cases continue to occur in both industrialized and non-industrialized countries [12].

Neisseria meningitidis is categorized into 12 serogroups according to the biochemical composition of the bacterial capsular polysaccharide [13]. However, only five serogroups (A, B, C, W, and $\mathrm{Y}$ ) are responsible for the majority of disease worldwide [14]; vaccines for the prevention of IMD caused by each of these serogroups are available. Currently licensed meningococcal serogroup A, C, W, Y (MenACWY) conjugate vaccines include MenACWY-CRM 197 (Menveo $^{\circledR}$; GlaxoSmithKline, Rixensart, Belgium), which is conjugated to the diphtheria protein cross-reactive material $197 \quad\left(\mathrm{CRM}_{197}\right)$ [15]; MenACWY-D $\quad$ Menactra $^{\circledR}$; Sanofi Pasteur, Swiftwater, PA, USA), which is conjugated to diphtheria toxoid (D) [16]; and MenACWY-TT (Nimenrix ${ }^{\circledR}$; Pfizer Inc, Sandwich, UK), which is conjugated to tetanus toxoid (TT) [17]. Available monovalent meningococcal serogroup $\mathrm{C}$ (MenC) vaccines include MenC-CRM 197 (Menjugate ${ }^{\circledR}$; GlaxoSmithKline Vaccines Srl, Siena, Italy) [18] and MenC-TT (NeisVac-C ${ }^{\mathrm{TM}}$; Pfizer Ltd, Kent, UK) [19], which use $\mathrm{CRM}_{197}$ and $\mathrm{TT}$, respectively, as carrier proteins. In addition, PsA-TT (MenAfriVac ${ }^{\text {TM}}$; Serum
Institute of India, Pune, India) is a meningococcal serogroup A (MenA) conjugate vaccine using TT as a carrier protein that was developed specifically to combat MenA disease in Africa [20]. Hib-MenC-TT (Menitorix ${ }^{\circledR}$; GlaxoSmithKline, Rixensart, Belgium) is a combination vaccine that includes MenC in addition to Haemophilus influenzae type b (Hib) [21]. The use of these polysaccharide conjugate meningococcal vaccines has collectively reduced the burden of meningococcal disease worldwide $[22,23]$.

Due to the poor immunogenicity of serogroup B capsular polysaccharide [24-26], two subcapsular antigen vaccines for the prevention of meningococcal serogroup B (MenB) disease have recently been developed: MenB-FHbp (Trumenba ${ }^{\circledR}$, bivalent rLP2086; Pfizer Inc, Philadelphia, PA, USA) [27] and MenB-4C (Bexsero $^{\circledR}$, 4CMenB; GlaxoSmithKline Vaccines Srl, Siena, Italy) [28]. MenB-FHbp is composed of two recombinant lipidated factor $\mathrm{H}$ binding proteins (FHbp), one variant each from subfamilies A and B. MenB-4C contains neisserial adhesin $\mathrm{A}$, neisserial heparin-binding antigen, and a nonlipidated FHbp variant from subfamily $\mathrm{B}$, in addition to outer membrane vesicles [28]. Vaccines for the prevention of MenB disease may provide some cross-protection against strains from other serogroups, including meningococcal serogroup X (MenX) [29, 30], which emerged recently in Africa [31].

Based on the rapid and severe clinical presentation of IMD, relative ease of transmission via respiratory secretions, and unpredictability of IMD incidence and epidemiology, protection can best be achieved by initiating proactive rather than reactive vaccination strategies [32]. Herd protection (i.e., protection of unvaccinated individuals) can be an important component of vaccination-mediated disease control, which occurs by limiting bacterial acquisition and thus transmission from vaccinated to unvaccinated individuals; this phenomenon has been particularly evident for certain MenC vaccination programs (i.e., in the Netherlands, United Kingdom, and Australia) [33-35]. Evidence also exists of reduced meningococcal carriage associated with MenA vaccine use in Africa [36]. Optimized 
vaccination strategies require continual adaptation to include available vaccines and thus ensure protection against emerging diseasecausing strains.

This article details recent changes in IMD epidemiology, the associated shifts in meningococcal vaccination recommendations, and data from clinical studies of MenACWY-TT, the most recently approved MenACWY vaccine [17]. Other MenACWY conjugate vaccines that were licensed earlier (MenACWY-D and MenACWY$\left.\mathrm{CRM}_{197}\right)[15,16]$ are also briefly summarized; their use has been previously described in detail [37]. Additionally, although many regions have multiple MenACWY vaccines licensed, some vaccination programs only use MenACWY-TT [38-40]. This article is based on previously conducted studies and does not contain any new studies with human participants or animals performed by any of the authors.

\section{Recent Changes in Meningococcal Epidemiology and Vaccination Recommendations}

Global shifts in meningococcal epidemiology coupled with a growing body of data regarding MenACWY vaccines have prompted changes in meningococcal vaccine recommendations in various countries (Table 1) [38, 39, 41-69]. Epidemiologic shifts and any associated changes in recommendations are summarized for select countries below.

\section{The United Kingdom}

The United Kingdom has been experiencing a pronounced increase in meningococcal serogroup W (MenW) disease since 2010 [70], with the number of reported MenW cases in England increasing more than tenfold from 2009-2010 (22 cases) to 2016-2017 (225 cases) [41]. Adults $\geq 45$ years old were the primary age group initially affected, but over time, MenW IMD increased in all age groups. Genetic analysis demonstrated that a majority of the MenW isolates responsible for the initial rapid increase belonged to a single clone of clonal complex 11 (cc11) [70].

Due to this rapid increase in MenW IMD, in September 2015 MenACWY vaccination
(MenACWY-CRM ${ }_{197}$ or MenACWY-TT) replaced the previous recommendation for monovalent MenC vaccination for adolescents [42]. The new vaccination program was directed at adolescents in school year 9, with the strategy of reducing transmission by targeting the age group preceding that in which meningococcal carriage rates begin to drastically increase $[42,71]$. Public Health England reported vaccination coverage rates of $71.4-83.6 \%$ by August 2017 [72]. The program also included catch-up vaccination for students $14-18$ years of age as well as those $<25$ years of age who were entering university [42]. MenACWY vaccination coverage in England among students who left school in $2015-2016$ was $36.6 \%$ by June 2016 [73]. During the first year of the program, the number of MenW cases in school leavers decreased by $69 \%$, with 6 confirmed cases (all unvaccinated) versus 19.4 predicted cases [73].

\section{France}

MenW disease has increased in France, beginning in 2015, and accounted for 9\% of all IMD notifications in 2016, with an incidence rate of 0.07 per 100,000 [43]. Compared with cases from other serogroups, older individuals had a higher incidence of MenW IMD and exhibited a higher case-fatality rate. As in the United Kingdom [70], multilocus sequence typing revealed that the MenW cases responsible for the upsurge in France were dominated by cc11; this was in contrast to endemic MenW disease caused largely by cc22 [43]. The increase in MenW IMD in France includes a 2017 outbreak among French university students that involved two cases and one death [8]. To date, France continues to recommend only MenC vaccination to infants and toddlers [45]. Of note, the vaccine schedule in France was modified in 2016 to include a MenC dose at 5 months of age, in addition to a second dose at 12 months of age, due to the persistent burden of MenC disease $[45,74]$.

\section{Italy}

Meningococcal epidemiology in Italy has demonstrated recent trends that differ from those of many other countries. In 2011, 


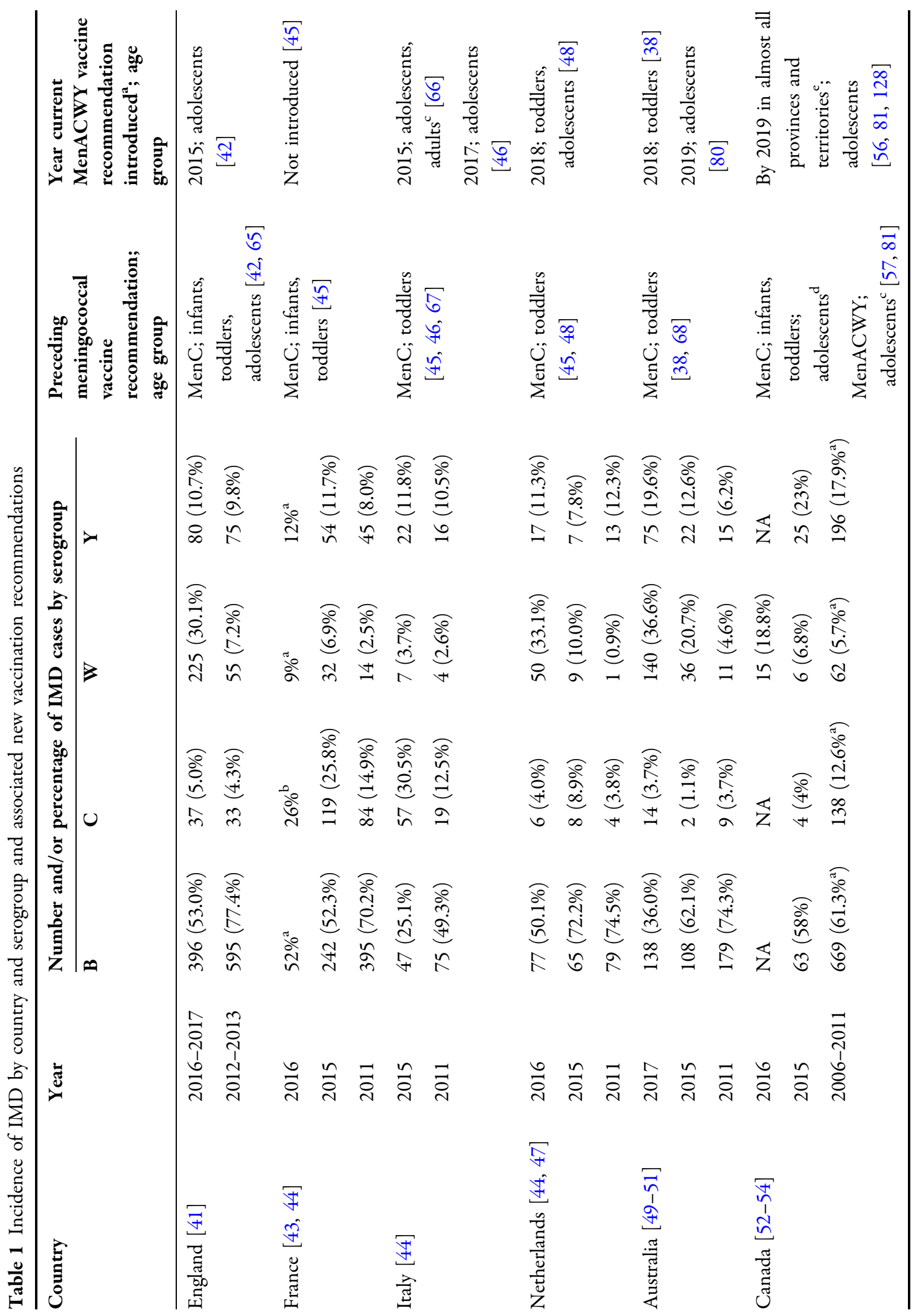




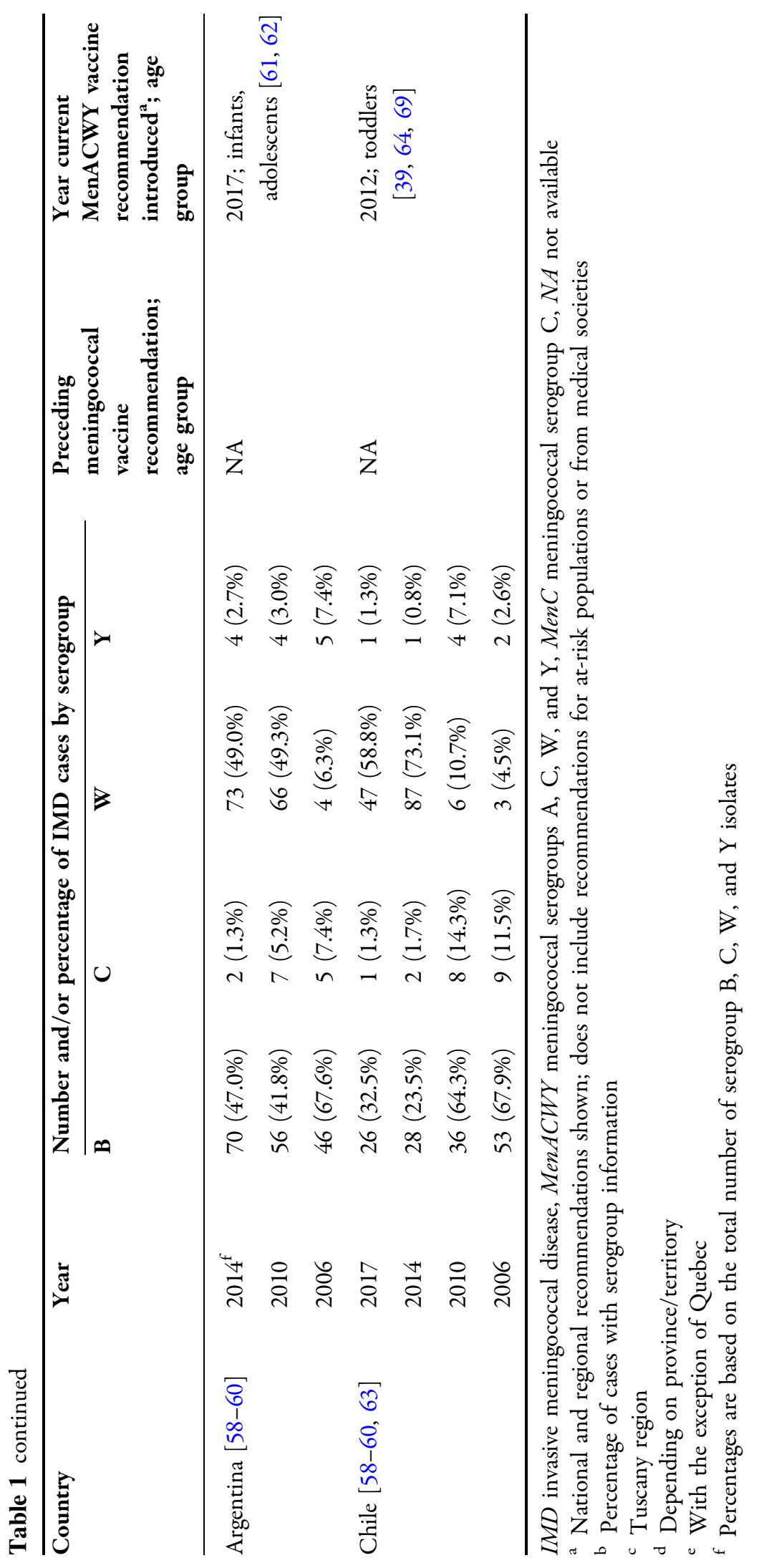


serogroups B, C, W, and Y accounted for $49.3 \%$ (75/152), $12.5 \%$ (19/152), $2.6 \%(4 / 152)$, and $10.5 \%(16 / 152)$ of cases, respectively [44]. By 2015, MenC accounted for $30.5 \%$ (57/187) of cases [44]; this increase reflected an outbreak that began in the Tuscany region in which 61 MenC cases were reported during 2015-2016 [67]. Genomic analysis indicated that the invasive strain belonged to cc11 [67]. In response, the Regional Health Authority of Tuscany offered MenACWY as a single dose to adolescents 11-19 years of age; the vaccine was also available to individuals 20-44 years of age residing in affected regions [66]. MenACWY was integrated into Italy's national immunization program (NIP) in 2017 as a single dose given to adolescents 12-14 years of age; although the national recommendation is that toddlers continue to receive a single MenC dose, several regions (e.g., Veneto, Emilia-Romagna, and Puglia) now recommend MenACWY in this age group [45, 46, 75-77].

\section{The Netherlands}

Children in the Netherlands have been routinely vaccinated against MenC since 2002, leading to a sustained reduction in MenC incidence [47]. However, starting at the end of 2015, MenW incidence drastically increased, accounting for approximately one-third of all IMD cases in 2016 at an incidence rate of 0.29 per 100,000. Incidence was highest in those $\geq 65$ years of age, followed by those $15-24$ years of age and then those $<5$ years of age. In response to this increase, beginning in 2018, MenACWY vaccination (using MenACWY-TT) targeting toddlers 14 months of age and adolescents 13-14 years of age was added to the NIP $[40,47,48]$.

\section{Australia}

In Australia, MenC vaccine was introduced in 2003, resulting in a significant reduction in MenC IMD [23]. MenB then predominated until 2015 despite a substantial decline in the number of MenB cases over that time [51]. However, MenW cases increased over eightfold from 2014 (17 cases) to 2017 (140 cases), with MenW becoming the predominant serogroup in 2016; similar to other countries, the increase was largely attributed to cc11 [51]. An increase in meningococcal serogroup $\mathrm{Y}$ (MenY) notifications has also occurred since 2011 [51]. Similar to the high fatality rates observed in cases of MenW disease in France [43], MenW cases in Australia in 2017 had a higher case-fatality rate (11.4\%) than MenB (5.9\%), MenY (4.1\%), or MenC cases (7.1\%) [51]. Several states instituted school-based programs using MenACWY for adolescents approximately $15-19$ years of age in response to the increasing number of MenW cases [78]. Additionally, a MenW outbreak originating in central Australia and affecting a number of other states prompted several regions to initiate temporary MenACWY vaccination programs [78]. As in the United Kingdom and the Netherlands, the Australian government recently integrated MenACWY into the NIP in response to increasing MenW incidence, with a program targeting toddlers 12 months of age (who were previously recommended to receive MenC) [38]. The program started on July 1, 2018, and specifies use of MenACWY-TT $[68,79]$. More recently, the Australian government announced that MenACWY will be added to the NIP in April 2019 under a school-based program targeting adolescents 14-16 years of age; catch-up vaccination will also be available for those 15-19 years of age [80].

\section{Canada}

The proportion of IMD caused by MenW in Canada dramatically increased to $18.8 \%(15 / 80)$ in 2016, nearly triple that reported in 2015 $(6.8 \%, 6 / 88)$ [52]. Genomic analysis tied the recent increase in MenW disease to the rise of cc11, whereas MenW disease before 2014 was generally caused by cc22 isolates. Interestingly, MenW cases caused by cc11 occurred predominantly in older individuals (median age, 53.5 years) compared with cc22 cases (median age, 23.5 years). Canadian children generally receive a MenC vaccine at 12 months of age, with some provinces administering additional doses in infancy, whereas adolescents receive one dose of either MenC or MenACWY, depending on the province [81]. In September 2016, British Columbia changed its vaccination recommendations for younger adolescents from 
MenC to MenACWY [56]. The next year, the Okanagan region in British Columbia experienced a MenW outbreak in older adolescents (15-19 years of age), prompting a temporary MenACWY vaccination program in this age group as well [82].

\section{Argentina}

Increases in MenW IMD occurred earlier in Argentina than in other countries. MenW accounted for just $6.3 \%(4 / 64)$ of all IMD isolates across all age groups in 2006 [58]; this increased to $49.3 \%(66 / 134)$ by 2010 [59] and remained steady through 2014 (49.0\%; 73/149) [60]. In 2014, the highest proportions of MenW occurred in infants and toddlers (47.1-66.7\%) and adults $\geq 30$ years of age (75-90\%). Consistent with observations from other countries, the increase in MenW was shown to be associated with cc11 strains [83]. In a 3-year prospective surveillance study conducted from 2012 to 2015 at six pediatric hospitals in Argentina, 42.9\% $(36 / 84)$ of the $N$. meningitidis isolates serogrouped were MenW [84]. In this study, a significant association between MenW and age $<1$ year was observed (odds ratio 3.18; 95\% CI 1.14-8.99), with $66.7 \%(24 / 36)$ of MenW cases occurring in this age group. In 2016, the Ministry of Health in Argentina released new recommendations in which MenACWY-CRM 197 would be administered at 3,5 , and 15 months of age, with an additional dose at 11 years of age [61]. These recommendations were included in the 2017 Argentina vaccination calendar [62].

\section{Chile}

The increase of MenW IMD in Chile occurred somewhat differently than in Argentina. In 2006 , only $4.5 \%(3 / 67)$ of cases were caused by MenW [58], increasing to $10.7 \%(6 / 56)$ in 2010 [59]. MenW disease incidence drastically increased thereafter, accounting for nearly three-quarters $(73.1 \% ; 87 / 119)$ of IMD in Chile in 2014 [60]. Proportions were high in most age groups in 2014 , especially infants $(65.8 \%)$ and individuals aged $\geq 5$ years $(75-100 \%)$. By 2017 , MenW had decreased to $58.8 \%$ (47/80) of isolates [63]. Similar to other global observations, a recently published study found that, among
119 IMD isolates collected in Chile, all MenW isolates (66\%) were identified as cc11 [85]. As a result of increasing MenW prevalence, the Chilean Ministry of Health initiated a MenACWY vaccination program in 2012 targeting children aged $\geq 9$ months to $<5$ years, and a single MenACWY-TT dose at 12 months of age was added to the NIP in 2014 [39, 64, 69]. In the years that followed, the number of cases substantially decreased in the age groups targeted for vaccination, but no herd protection was observed, likely due to the age group vaccinated [39].

\section{MenACWY-D and MenACWY-CRM 197 Vaccines}

Of the three currently available MenACWY conjugate vaccines, MenACWY-D [16] and MenACWY-CRM 197 [15] were approved earlier, whereas MenACWY-TT [17] is the most recently licensed. Safety and immunogenicity of all three vaccines have been evaluated throughout a large part of the human lifespan (i.e., in infants, toddlers, children, adolescents, and adults) $[15-17,86]$, but the availability of each vaccine varies across different regions of the world [87]. In the United States, MenACWY-D and MenACWY-CRM 197 are available, but MenACWY-TT is not currently approved $[87,88]$. In contrast, MenACWY-D is not currently licensed in the European Union, where MenACWY-CRM 197 and MenACWY-TT are used instead $[17,89,90]$. Additionally, the ages for which the vaccines are licensed can vary both between vaccines and between countries for a particular vaccine.

\section{MenACWY-D}

MenACWY-D is available in several countries, including some of those experiencing recent MenW disease increases, such as Australia, Canada, Argentina, and Chile [89]. Ages for which the vaccine is approved differ by country. For instance, in Canada, it is approved for use in individuals 9 months to 55 years of age [91]. For children 9-23 months of age, the manufacturer recommends that MenACWY-D be administered in two doses given at least 3 months apart. 
In individuals 2-55 years of age, MenACWY-D is administered as a single dose. In the United States, if 4 years have passed since the previous vaccination dose, a single booster dose may be administered to individuals $15-55$ years of age who are at continued risk for meningococcal disease [16]. The immunogenicity of MenACWY-D has been described previously, with reports of $\geq 86.4 \%$ of subjects 1 year of age having serum bactericidal assays using human complement (hSBA) titers $\geq 1: 8$ for each of the four serogroups 1 month after a second dose [91]. Additionally, $\geq 96.2 \%$ of children 2-10 years of age had SBA titers $\geq 1: 8$ across the four vaccine serogroups 28 days after vaccination. Commonly reported reactions following MenACWY-D administration include injection site tenderness or pain and irritability in children and injection site pain, headache, and fatigue in adults.

\section{MenACWY-CRM 197}

Similar to MenACWY-D, MenACWY-CRM ${ }_{197}$ is approved in many countries experiencing recent MenW disease increases, including the United Kingdom, France, Netherlands, Australia, Canada, Argentina, and Chile, among others [90]. In the European Union, MenACWY$\mathrm{CRM}_{197}$ is approved for individuals 2 years and older, who are given a single dose [92]. In the United States, on the other hand, the vaccine is approved from 2 months of age, with recommended dosing for infants varying by age at initiation [15]. A booster dose can be given according to recommendations in both regions $[15,92]$. In children $2-10$ years of age, $\geq 68 \%$ had hSBA titers $\geq 1: 8$ across the four serogroups at 1 month after a single dose; percentages were $\geq 75 \%$ in adolescents $11-18$ years of age and $\geq 69 \%$ in adults $19-55$ years of age [92]. Commonly reported reactions after MenACWY$\mathrm{CRM}_{197}$ dosing include pain, firmness, and erythema at the injection site and sleepiness, headache, irritability, and generally feeling unwell in children; and pain, firmness, and erythema at the injection site and nausea, headache, myalgia, and generally feeling unwell in adolescents and adults.

\section{Review of Recent MenACWY-TT Studies}

The recommendations for MenACWY vaccination in most of the reviewed countries include the most recently approved quadrivalent vaccine, MenACWY-TT [17, 39, 40, 42, 93]. MenACWY-TT is licensed throughout a large part of the lifespan (i.e., 6 weeks of age and older) $[17,86]$. Several studies conducted in infants, toddlers, children, and adolescents have supported the expanded recommendations for MenACWY-TT vaccine use; these are summarized below and in Table 2 [94-107].

\section{Infant Studies}

In a noninferiority study conducted in Europe, 2095 infants were randomized to receive MenACWY-TT at 2, 3, 4, and 12 months of age; MenACWY-TT at 2, 4, and 12 months of age; MenC-CRM 197 at 2, 4, and 12 months of age; or MenC-TT at 2, 4, and 12 months of age [94]. All subjects received other routine vaccinations as recommended. Immunogenicity was assessed 1 month after the primary infant series. A 2- or 3-dose primary series of MenACWY-TT was shown to be noninferior to a 2-dose primary series of MenC-CRM ${ }_{197}$ or MenC-TT in terms of the immune response to MenC. One month after primary vaccination, $\geq 93.1 \%$ of subjects had titers $\geq 1: 8$ in serum bactericidal assays using rabbit complement (rSBA) for the four serogroups, whereas $\geq 88.5 \%$ had titers $\geq 1: 8$ in assays using hSBA. Although proportions of subjects with titers $\geq 1: 8$ decreased by 12 months of age, immune responses to booster doses were robust, with $\geq 99.1 \%$ of subjects having rSBA or hSBA titers $\geq 1: 8$ a month after booster vaccination. MenACWY-TT vaccination was also demonstrated to be safe and tolerable.

In another study, MenACWY-TT was administered to 750 infants in a 2:1:1 randomization ratio with dosing at $2,4,6$, and 15-18 months of age; 6 and 15-18 months of age; or 15-18 months of age [95]. All infants also received additional routine vaccinations. Efficacy and safety measures were reported. Among those receiving a 3-dose primary series at 2,4 , and 6 months of age, $\geq 99.4 \%$ of subjects had rSBA titers $\geq 1: 8$ for each of the 


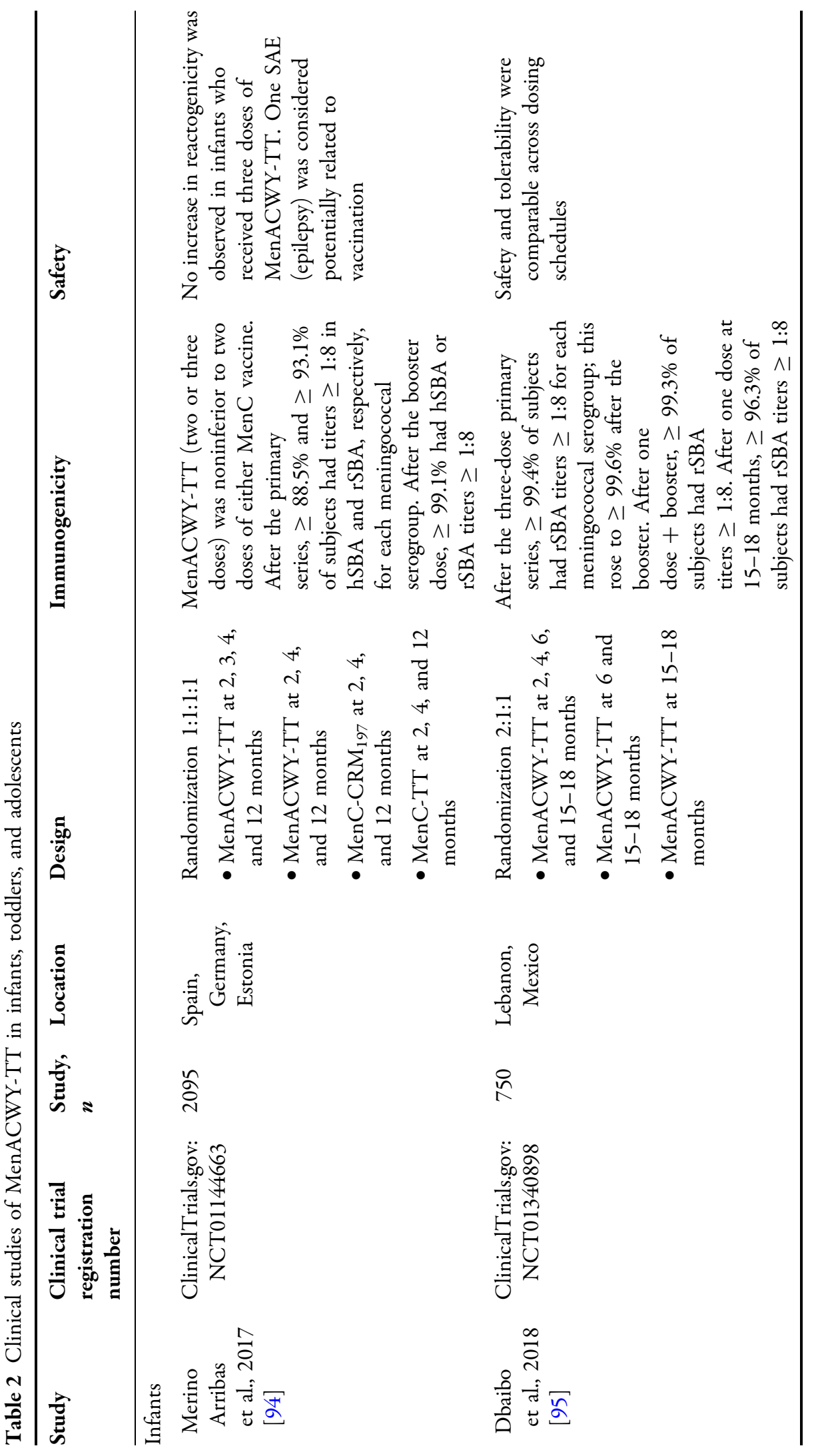




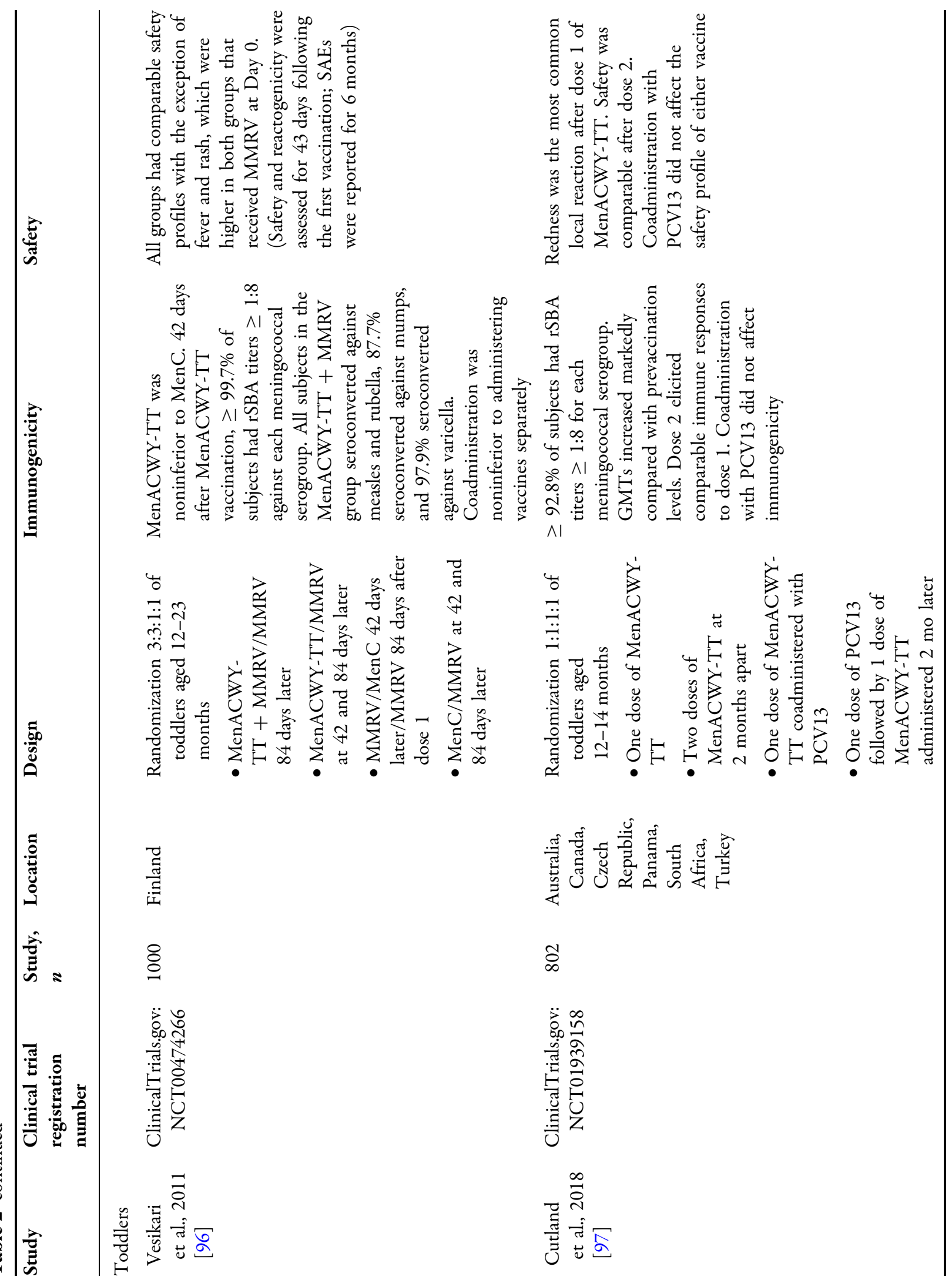




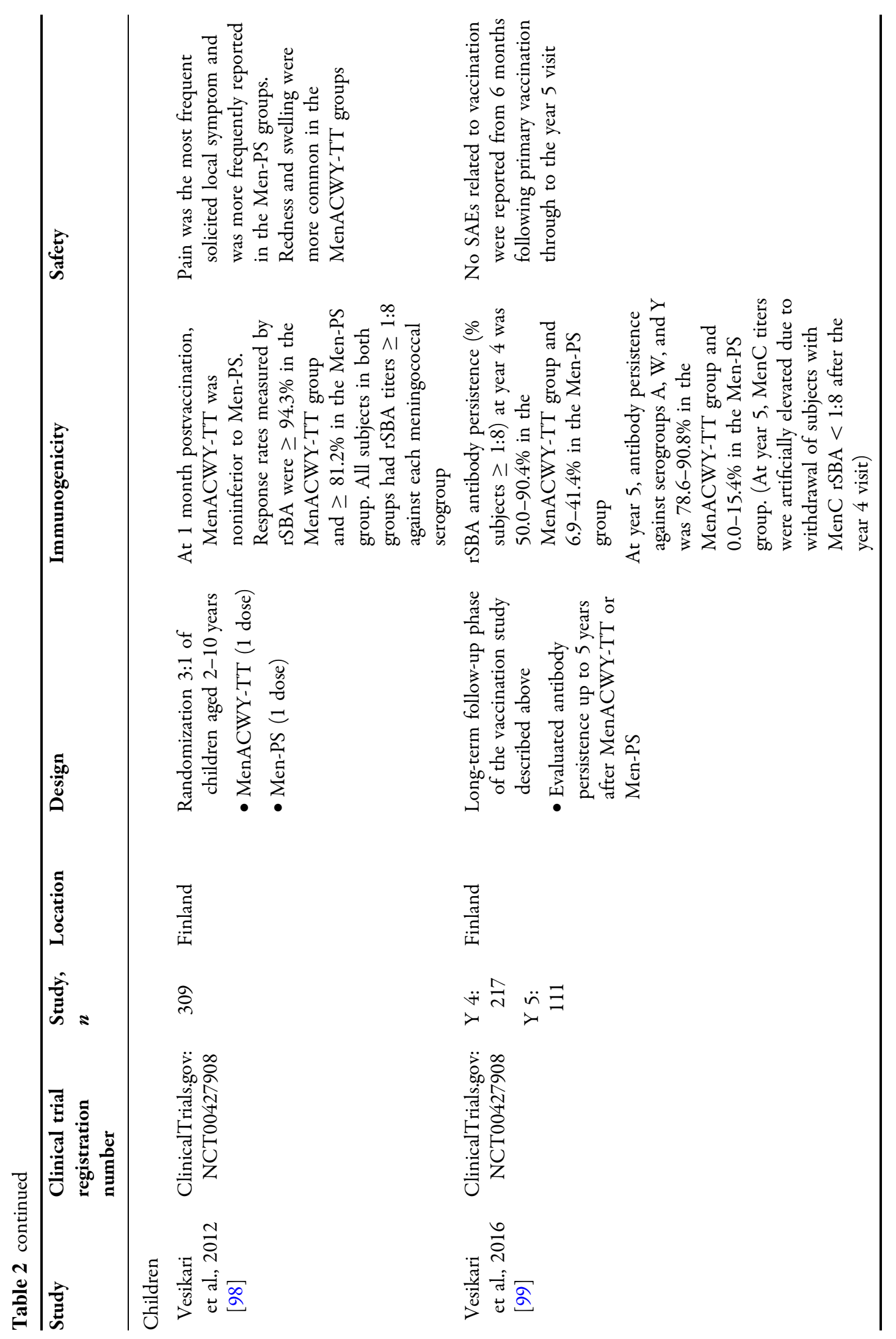




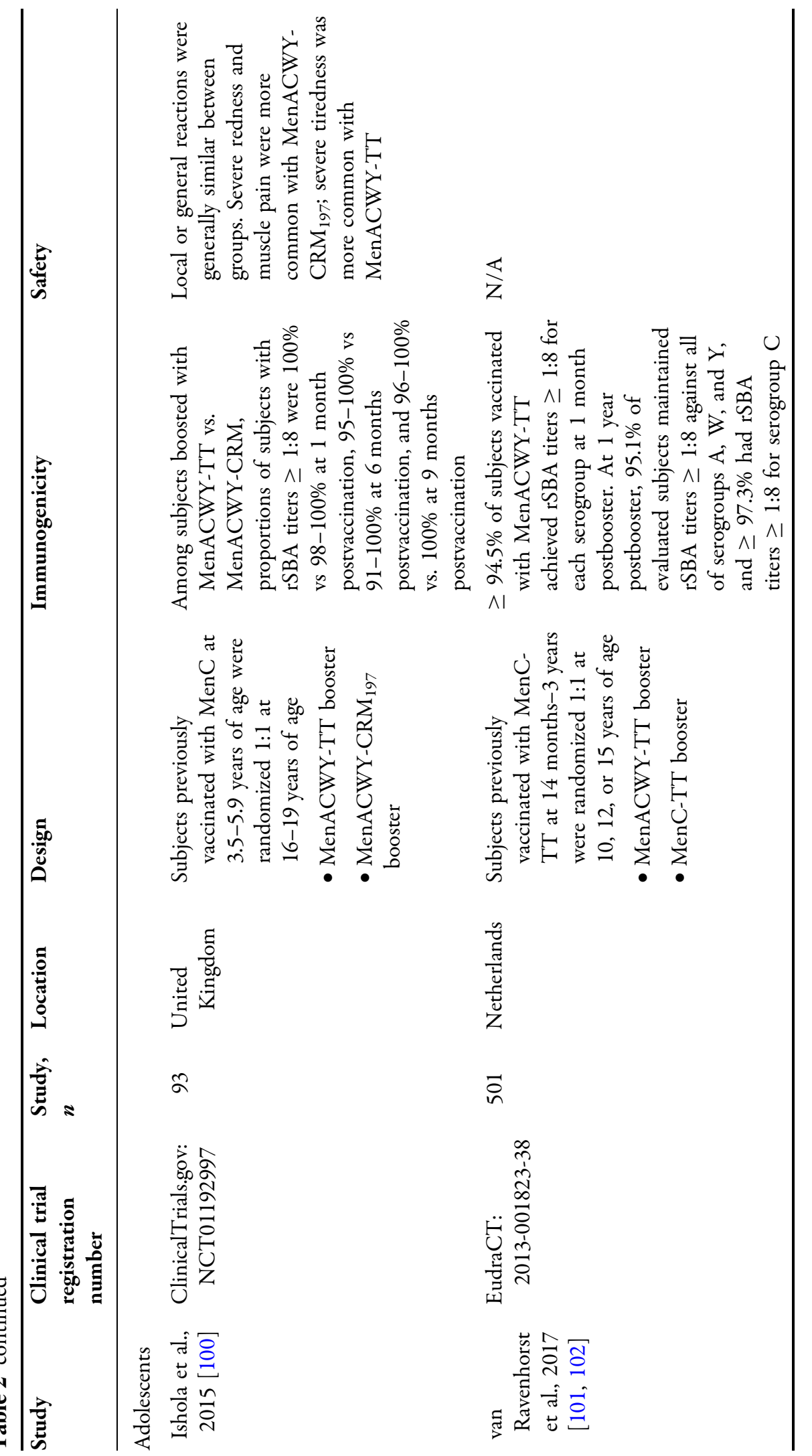




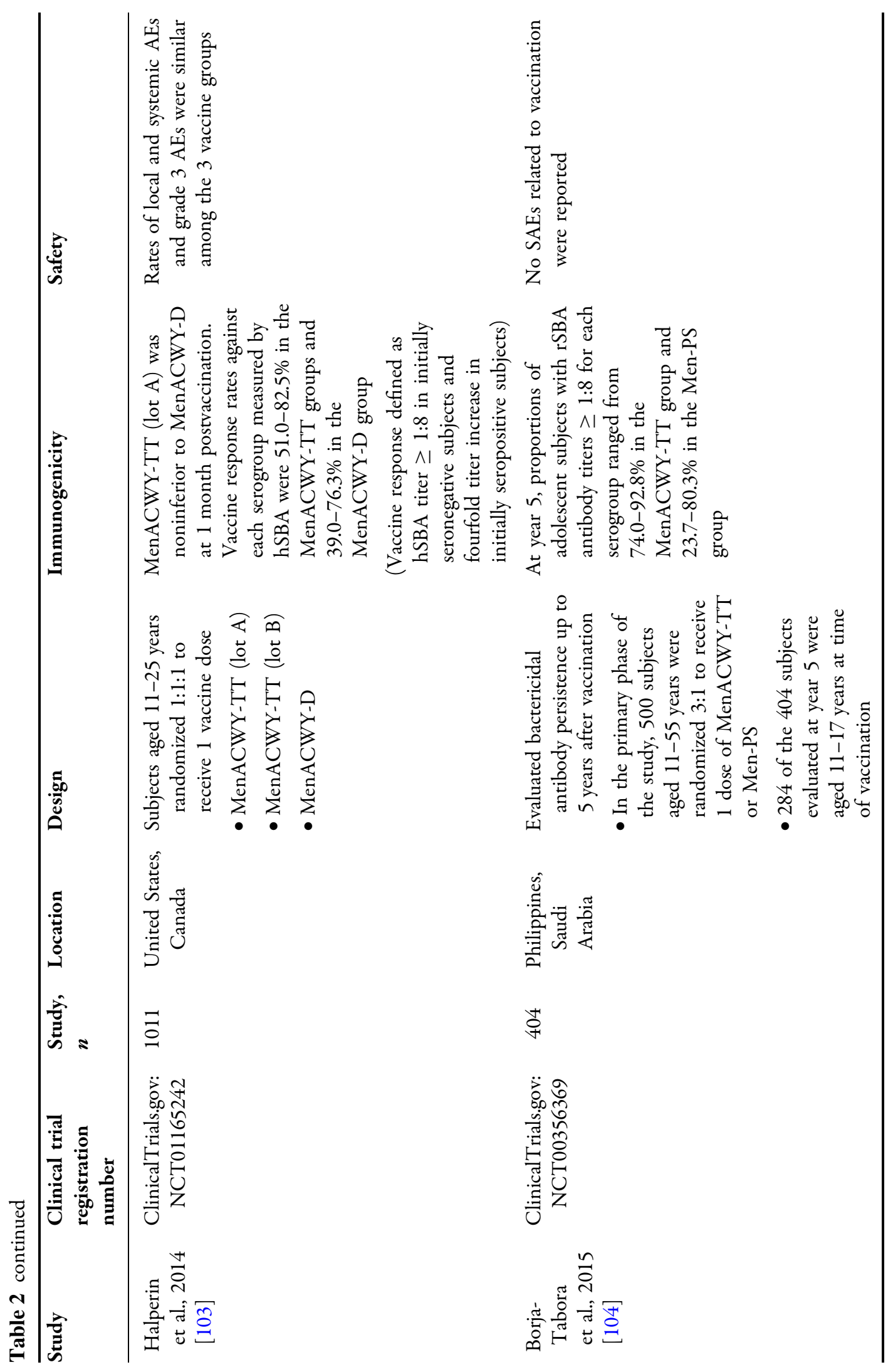




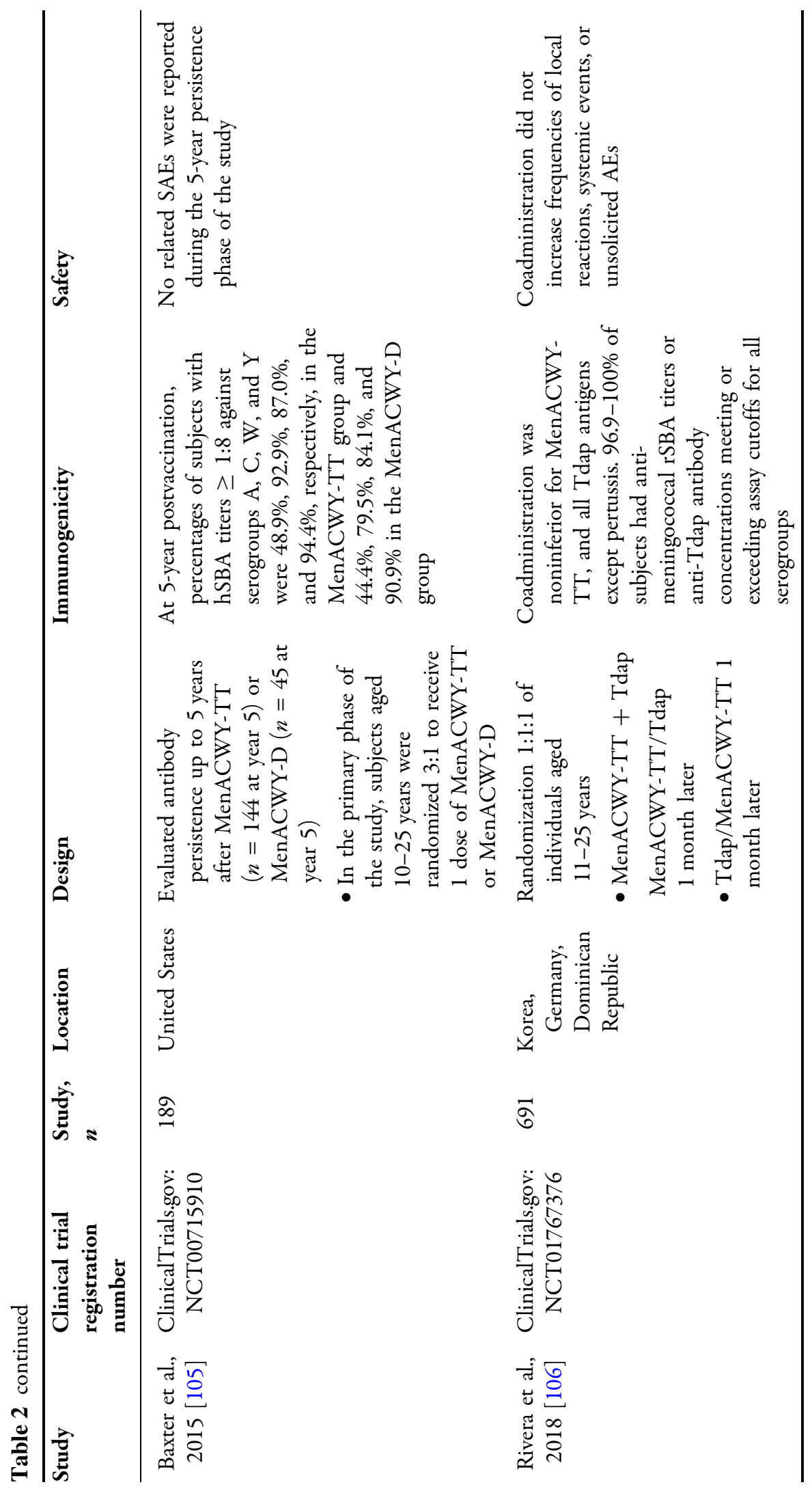




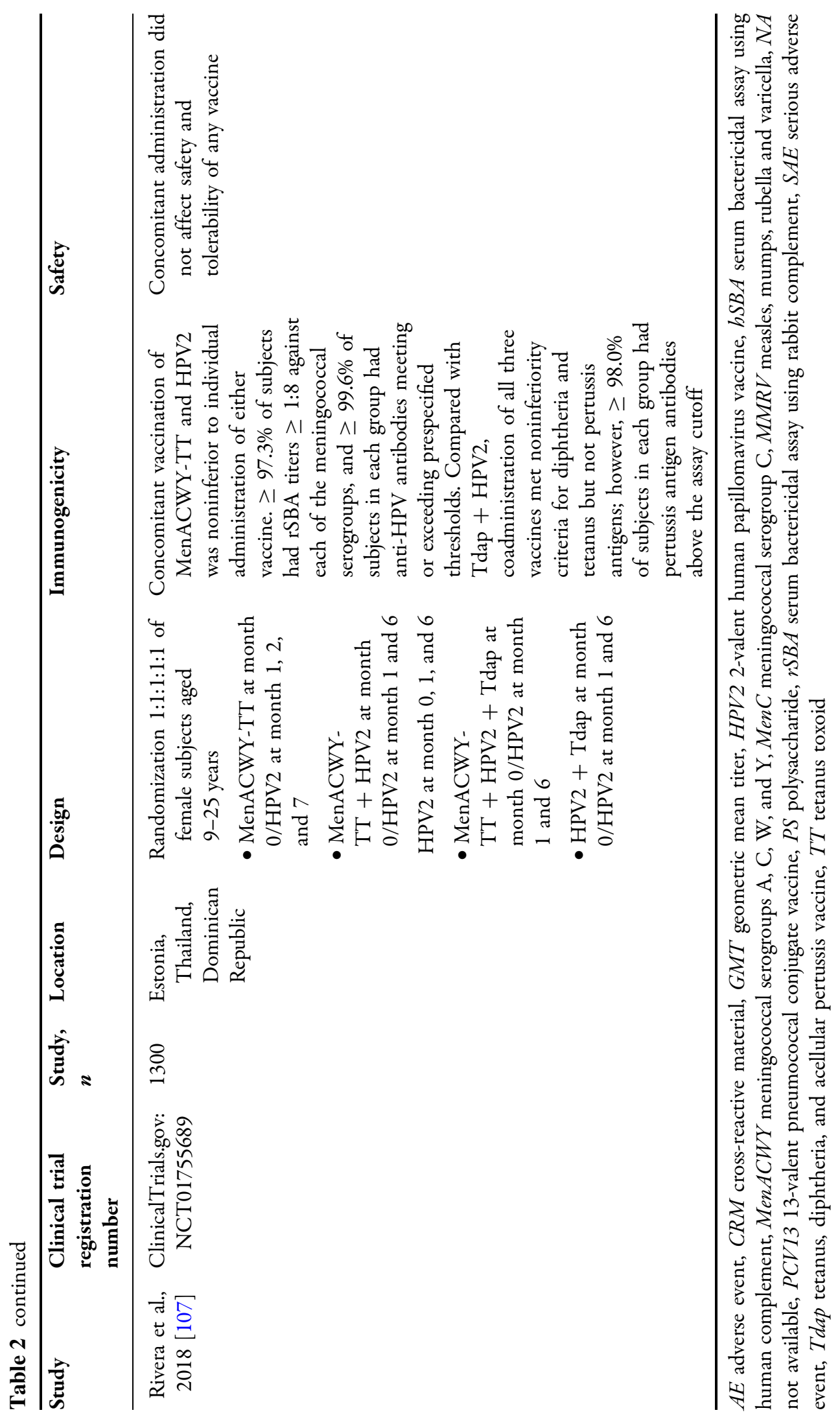


vaccine serogroups at 1 month after the third dose. Among subjects receiving 1 dose at 6 months and those receiving one dose at $15-18$ months, $\geq 93.9 \%$ and $\geq 96.3 \%$, respectively, had rSBA titers $\geq 1: 8$ for each of the four serogroups 1 month after vaccination. For groups that received a booster dose at $15-18$ months of age, $\geq 99.3 \%$ of subjects had rSBA titers $\geq 1: 8$ for each of the four serogroups at 1 month after booster vaccination. Proportions of subjects reporting local reactions, systemic events, adverse events (AEs), and serious AEs (SAEs) were similar across groups after primary and booster vaccinations. None of the SAEs were considered vaccine-related.

\section{Toddler Studies}

In a study conducted in 1000 toddlers aged 12-19 months in Finland, subjects were randomized 3:3:1:1 to 1 of 4 treatment groups [i.e., MenACWY-TT + measles, mumps, rubella, and varicella (MMRV) vaccine; MenACWY-TT alone; MMRV alone, or MenC-CRM ${ }_{197}$ [ [96]. One dose of MenACWY-TT was shown to be noninferior to MenC-CRM ${ }_{197}$ for immunogenicity against serogroup $\mathrm{C}$ and was also immunogenic against serogroups A, W, and Y. Forty-two days after vaccination with a single dose of MenACWY$\mathrm{TT}, \geq 99.7 \%$ of subjects had $\mathrm{rSBA}$ titers $\geq 1: 8$ against each vaccine serogroup; $\geq 99.4 \%$ also had titers $\geq 1: 128$ against serogroups $\mathrm{A}, \mathrm{W}$, and Y. Among subjects in the MenACWY-TT + MMRV and MMRV groups, all seroconverted against measles and rubella; $87.7 \%$ and $83.6 \%$, respectively, had seroconverted against mumps; and $97.9 \%$ and $94.6 \%$ had seroconverted against varicella by 42 days postvaccination. Noninferiority was demonstrated for concomitant versus individual administration. Fever and rash occurred at a similar frequency in the MenACWY-TT + MMRV and MMRV groups; these frequencies were higher than those observed in the MenACWY-TT and MenC$\mathrm{CRM}_{197}$ groups. Safety profiles were otherwise comparable across groups.

A phase 3 study was conducted in 802 toddlers 12-14 months of age in Australia, Canada, Czech Republic, Panama, South Africa, and Turkey, with subjects randomized to receive one dose of MenACWY-TT, two doses of
MenACWY-TT at 2 months apart, one dose of MenACWY-TT coadministered with 13-valent pneumococcal conjugate vaccine (PCV13), or one dose of PCV13 followed by one dose of MenACWY-TT administered 2 months later [97]. At 1 month postvaccination, $\geq 92.8 \%$ of toddlers vaccinated with MenACWY-TT had rSBA titers $\geq 1: 8$ for the four serogroups, and geometric mean titers (GMTs) increased substantially compared with titers before vaccination. Responses were robust and slightly higher after two doses compared with one dose. Coadministration of MenACWY-TT and PCV13 did not alter the safety or immunogenicity profile of MenACWY-TT.

\section{Child Studies}

In a phase 2 study, 309 children aged $2-10$ years in Finland were randomized 3:1 to receive one dose of MenACWY-TT or a licensed meningococcal MenACWY polysaccharide vaccine (Men-PS) [98]. The study assessed vaccine response rates, which were defined as a postvaccination $\mathrm{rSBA}$ titer $\geq 1: 32$ for seronegative children (rSBA titer $<1: 8$ at prevaccination) and $\geq$ fourfold increase in rSBA titer from prevaccination to postvaccination for seropositive children (rSBA titer $\geq 1: 8$ at prevaccination). At 1 month postvaccination, MenACWY-TT was noninferior to Men-PS with rSBA response rates $\geq 94.3 \%$ in the MenACWY-TT group and $\geq 81.2 \%$ in the Men-PS group. Exploratory analyses demonstrated that response rates and rSBA GMTs were higher among MenACWY-TT than Men-PS recipients, and a higher percentage of subjects had rSBA titers $\geq 1: 128$ for serogroup $C$ in the MenACWY-TT group versus the Men-PS group. In the MenACWY-TT and MenPS groups, pain was the most frequent solicited local symptom in children aged 2-5 years (45.1\% and $71.8 \%$, respectively) and $6-10$ years (71.8\% and $82.1 \%$, respectively); redness and swelling were more common in the MenACWYTT groups [98].

A follow-up study evaluated the persistence of serum bactericidal antibodies in these subjects up to 5 years after receiving MenACWY-TT or Men-PS [99]. At year 5, the proportion of subjects in the MenACWY-TT group $(n=98)$ with $\mathrm{rSBA}$ titers $\geq 1: 8$ for serogroups $\mathrm{A}, \mathrm{C}, \mathrm{W}$ 
and $\mathrm{Y}$ were $90.8 \%, 90.8 \%, 78.6 \%$, and $78.6 \%$, respectively; in the Men-PS group $(n=13)$, these proportions were $15.4 \%, 100 \%, 0.0 \%$, and $7.7 \%$, respectively. Exploratory analyses indicated that differences between the vaccine groups were significant for serogroups $\mathrm{A}, \mathrm{W}$, and Y. As individuals with rSBA-MenC titers $<1: 8$ at any time during the study were revaccinated with a MenC conjugate vaccine and withdrawn from further analyses, interpretation of serogroup $\mathrm{C}$ antibody persistence in the remaining subjects was difficult.

\section{Adolescent and Young Adult Studies}

A study of 93 British adolescents 16-19 years of age who had been previously vaccinated with MenC-TT or MenC-CRM 197 at 3.5-5.9 years of age compared immunogenicity and safety of MenACWY-TT with MenACWY-CRM 197 [100]. Of the 92 participants with available data, nearly all had protective rSBA titers (i.e., $\geq 1: 8$ ) for all serogroups at 1 month after booster in both groups, with the exception being for serogroup $\mathrm{Y}$ in one subject boosted with MenACWY-CRM ${ }_{197}$. The highest titers were measured in subjects primed with MenC-TT and boosted with MenACWY-TT. A high proportion of subjects in both MenACWY booster groups had protective titers through 9 months after booster. Both vaccines were well tolerated, although redness and muscle pain were comparatively more common among MenACWY$\mathrm{CRM}_{197}$ recipients, and tiredness was more common among MenACWY-TT recipients. No vaccine-related SAEs occurred in either group.

A similar study assessed MenACWY-TT boosting in 501 Dutch adolescents aged 10, 12, and 15 years who had previously received the MenC vaccine at 14 months to 3 years of age [102]. All children had been primed with MenCTT, and booster vaccinations used either MenACWY-TT or MenC-TT. One month after booster dosing, all participants except one had rSBA titers $\geq 1: 8$ for serogroup $C$; however, noninferiority for MenACWY-TT compared with MenC-TT could not be demonstrated for the subjects in the 10- and 15-year-old age groups. rSBA GMTs significantly declined in all age groups by 1 year after booster dosing, and noninferiority could not be demonstrated for any age group; however, all but two participants maintained rSBA titers $\geq 1: 8$. Importantly, the decline in protective antibodies was fastest in the 10-year-old age group, which may be important in determining optimal ages for vaccination.

Results from this study for serogroups A, W, and $\mathrm{Y}$ were reported in a separate publication and indicated that GMTs significantly increased at 1 month after MenACWY-TT vaccination [101]. MenW and MenY GMTs were higher in the 15-year-old age group compared with the 10-year-old age group, and MenA and MenY GMTs were higher in the 12-year-old age group compared with the 10-year-old age group; $100 \%$ of subjects in the 12- and 15-year-old age groups and $\geq 94.5 \%$ in the 10-year-old age group achieved rSBA titers $\geq 1: 8$ for all three serogroups. At 1 year after booster, $95.1 \%$ of subjects maintained rSBA titers $\geq 1: 8$ against all three serogroups, and MenW GMTs in the 10-year-old age group were significantly lower than in the other age groups, again suggesting that vaccination after earlier adolescence might maximize effectiveness.

The safety and immunogenicity of MenACWY-TT were compared with that of MenACWY-D in Canadian and US adolescents and young adults in a phase 2 clinical study [103]. Subjects were randomized to receive a single dose of MenACWY-TT ( 1 of 2 lots, with lot $\mathrm{A}$ and lot $\mathrm{B}$ having $68 \%$ and $92 \%$ O-acetylation of the MenA polysaccharide, respectively) or MenACWY-D. Vaccine response was defined as an hSBA titer $\geq 1: 8$ in initially seronegative subjects or a fourfold increase in titer in subjects who were initially seropositive. At 1 month after vaccination, vaccine response rates for the four serogroups ranged from 51.2 to $77.2 \%$ in subjects vaccinated with MenACWY-TT lot A, $51.0-82.5 \%$ in subjects vaccinated with MenACWY-TT lot B, and 39.0-76.3\% in subjects vaccinated with MenACWY-D. The primary study objective, noninferiority of MenACWYTT (lot A) compared to MenACWY-D with respect to hSBA responses against each serogroup, was demonstrated. Local and systemic events were comparable among the three vaccine groups, and the frequency of SAEs was 
similar in MenACWY-TT and MenACWY-D vaccinated subjects.

The persistence of the bactericidal antibody response was compared in US subjects who had been randomized 3:1 to receive one dose of MenACWY-TT or MenACWY-D at 10-25 years of age [105]. Five years postvaccination, the proportions of subjects with hSBA titers $\geq 1: 8$ against serogroups $\mathrm{A}, \mathrm{C}, \mathrm{W}$, and $\mathrm{Y}$ were $48.9 \%$, $92.9 \%, 87.0 \%$, and $94.4 \%$, respectively, in the MenACWY-TT group and 44.4\%, 79.5\%, 84.1\%, and $90.9 \%$ in the MenACWY-D group. In the MenACWY-TT group, serogroup $\mathrm{C}, \mathrm{W}$, and $\mathrm{Y}$ hSBA GMTs remained above prevaccination levels at 5 years; in the MenACWY-D group, serogroup $\mathrm{W}$ and Y GMTs remained elevated. Exploratory analyses suggested that serogroup C and Y GMTs and the percentage of subjects with titers $\geq 1: 8$ against serogroup $C$ were higher in the MenACWY-TT group compared with the MenACWY-D group. No vaccination-related SAEs were reported during the 5 years of this study.

A study carried out in the Philippines and Saudi Arabia evaluated bactericidal antibody persistence and safety of MenACWY-TT in healthy adolescents and adults aged $11-55$ years at the time of vaccination [104]. Of the 500 subjects who were randomized 3:1 to receive one dose of MenACWY-TT or Men-PS, 404 vaccinated subjects returned at year 5: 299 subjects in the MenACWY-TT group (including $n=208$ subjects aged 11-17 years) and 105 subjects in the Men-PS group (including $n=76$ subjects aged 11-17 years). In the total year 5 cohort, the percentages of subjects with rSBA titers $\geq 1: 8$ for serogroups $\mathrm{A}, \mathrm{C}, \mathrm{W}$, and $\mathrm{Y}$ in the MenACWY-TT group were 90.0\%, 79.3\%, $71.6 \%$, and $84.3 \%$, respectively; corresponding values in the Men-PS group were 74.3\%, 71.2\%, $24.8 \%$, and $44.8 \%$, respectively. Exploratory analyses indicated that the percentages of subjects with rSBA titers $\geq 1: 8$ for serogroups $A, W$, and $Y$ were significantly higher in the MenACWY-TT group than the Men-PS group at year 5 . In both vaccine groups, rSBA antibody responses of the adolescent age group were consistent with those of the total population. No SAEs related to vaccination were reported during the 5-year study period.
Two recent studies addressed concomitant administration of MenACWY-TT with other vaccines commonly recommended to adolescents [106, 107]. In reviewing these studies, it is important to note that vaccination rates among adolescents are often low [73, 108, 109], and concomitant vaccination is an established strategy for increasing vaccine uptake $[110,111]$. The first study compared concomitant administration of MenACWY-TT and tetanus, diphtheria, and acellular pertussis vaccine (Tdap; Boostrix ${ }^{\circledR}$; GlaxoSmithKline, Rixensart, Belgium) [112] with sequential administration of the two vaccines in 691 adolescents aged 11-25 years from Korea, Germany, and the Dominican Republic. One month after vaccination, prespecified noninferiority criteria were met in the coadministration group for all four meningococcal serogroups (using rSBA GMTs) as well as for antibodies targeting diphtheria and tetanus but not for antibodies targeting pertussis antigens. Overall, $96.9-100 \%$ of subjects had anti-meningococcal rSBA titers or antiTdap antibody concentrations meeting or exceeding assay cutoffs for all serogroups and antigens tested. Coadministration did not increase frequencies of local reactions, systemic events, or unsolicited AEs, and none of the three SAEs reported across groups were considered vaccine-related.

An additional study in 1300 female subjects aged 9-25 years in Estonia, Thailand, and the Dominican Republic investigated concomitant administration of MenACWY-TT with 2-valent human papillomavirus (HPV2; Cervarix $^{\mathrm{TM}}$; GlaxoSmithKline, Rixensart, Belgium) [113] and Tdap vaccines [107]. Concomitant vaccination of MenACWY-TT and HPV2 with one another or with Tdap in addition was noninferior to individual administration of either vaccine. Across groups, $\geq 97.3 \%$ of subjects had rSBA titers $\geq 1: 8$ or $\geq 1: 128$ against each of the meningococcal serogroups, and $\geq 99.6 \%$ of subjects in each group had anti-HPV antibodies meeting or exceeding prespecified thresholds. Similar to the study assessing concomitant administration with Tdap, coadministration of all three vaccines met noninferiority criteria for diphtheria and tetanus but not pertussis antigens compared with coadministration of Tdap 
with HPV2 only; however, $\geq 98.0 \%$ of subjects in each group had pertussis antigen antibodies above the assay cutoff. Safety and tolerability of all vaccines were not affected by concomitant administration.

\section{DISCUSSION}

Vaccination is the best method for preventing IMD [37]. Coupled with the broad distribution of $\mathrm{A}, \mathrm{C}, \mathrm{W}$, and Y IMD serogroups worldwide and the potential for sporadic and unpredictable outbreaks, multivalent meningococcal vaccines provide the best prophylactic coverage against IMD. Several countries (United Kingdom, France, the Netherlands, Australia, and Chile) that included monovalent MenC in their national meningococcal vaccination recommendations have experienced recent notable increases in IMD due to MenW $[41,43,47,51,59]$. Recent global increases in MenW disease and resulting changes in vaccination programs are of critical importance and have been chronicled elsewhere in addition to the current review [114]. Increases were sometimes quite dramatic, such as the tenfold increase in MenW IMD in the United Kingdom that occurred from 2009-2010 to 2016-2017 [41]. In association with increased incidence, the United Kingdom, the Netherlands, Australia, and Chile, as well as other countries and regions, have opted to update meningococcal vaccination recommendations to replace monovalent MenC vaccine with quadrivalent MenACWY vaccines [38, 42, 69, 75-77, 115-117]. To similarly address recent changes in IMD epidemiology, Italy changed its vaccination recommendations to include an adolescent MenACWY vaccine dose to address a MenC outbreak that occurred in 2015-2016 [44-46, 67]. In some cases, the effects of MenACWY vaccination are already evident (e.g., United Kingdom, which had a 69\% decrease in the number of MenW cases in the first year of an emergency MenACWY vaccination program targeting matriculated high school students/college entrants) [73]. Epidemiologic surveillance over the coming years is expected to provide valuable insight into the protection afforded by broader serogroup coverage.

Currently, three conjugate quadrivalent vaccine formulations-MenACWY-CRM ${ }_{197}$, MenACWY-D, and MenACWY-TT-are in use globally [15-17]. Of these, MenACWY-TT is the most recently approved, with initial authorization in the European Union in 2012 [17] and approval in more than 40 other countries [88]. The TT carrier protein contained in the MenACWY-TT formulation provides good thermal stability and a large surface area for polysaccharide conjugation [118]. In addition, higher antibody titers postdosing have been reported with the TT protein than with the CRM protein [119-121]. The immunogenicity and safety profile of MenACWY-TT has been established in clinical studies and supports use across all age groups [17]. The European Medicines Agency license for MenACWY-TT currently specifies that infants 6 weeks to $<6$ months of age should be given two doses separated by 2 months, followed by a booster dose at 12 months of age with at least 2 months since the previous primary dose [17]. Infants from 6 months to $<12$ months of age should be given one dose, followed by a booster dose at 12 months of age or at least 2 months after the first dose. Toddlers from 12 months of age, children, adolescents, and adults are given a single dose; previously vaccinated individuals who are 12 months or older may be given a booster MenACWY-TT dose if previously vaccinated with a conjugated or plain polysaccharide meningococcal vaccine.

The available MenACWY conjugate vaccines induce protection against four of the five major disease-causing serogroups, the greatest number in a single vaccine. However, these vaccines will not prevent serogroup B infections, which are a predominant cause of IMD in many countries [23]. An adjunct vaccination strategy with recently introduced MenB vaccines should therefore be considered to provide protection against this serogroup. An innovative approach of combining these vaccines into a pentavalent entity is currently under evaluation. Two studies conducted in adolescents and young adults evaluated a pentavalent MenABCWY vaccine based on MenACWY-CRM 197 and MenB-4C 
compared with individual administration of both vaccines [122, 123]. Immune responses after two doses of the MenABCWY vaccine were high for all serogroups in both studies $[122,123]$, and an extension study also supported prime-boost strategies in those vaccinated with currently licensed MenB-4C or MenACWY-CRM 197 vaccines [124]. Another MenABCWY vaccine based on MenB-FHbp for the serogroup $B$ component is currently under clinical evaluation [125].

The addition of subcapsular antigens to capsular polysaccharide-based multivalent vaccines could also augment protection against non-MenB isolates (cross-protection), as shown by the high proportions of MenB-FHbp recipients with hSBA titers $\geq 1: 8$ against strains from serogroups C, W, X, and Y [30]. For MenB-4C, two studies suggested that sera from vaccinated subjects were capable of killing MenW and MenX strains [29, 126].

Although direct protection is an important component of meningococcal vaccination strategies, reducing meningococcal carriage and transmission can also be crucial for reducing IMD on a population level. In addition to inducing protective antibodies, meningococcal conjugate vaccines have the ability to reduce acquisition of nasopharyngeal carriage in those vaccinated and thus reduce subsequent transmission to the unvaccinated [127]. Protection of unvaccinated individuals (herd protection) has been observed with MenC conjugate vaccination in the United Kingdom, where decreases in IMD incidence were first evident in vaccinated individuals, followed by unvaccinated children and older adults [34]. Similar findings were observed with the use of MenC vaccine in the Netherlands, where MenC IMD decreased rapidly in all age groups, although only children and adolescents $\leq 18$ years of age were vaccinated [33]; such outcomes were also observed in Australia [35]. As mentioned previously, data also indicate reduced carriage following MenA vaccination in Africa [36]. Supportive data are still needed to address the potential of MenACWY vaccines to induce herd protection.

\section{CONCLUSION}

In summary, global shifts in IMD epidemiology, particularly the increased incidence of MenW IMD, have resulted in reactive vaccination recommendations in several countries. Quadrivalent conjugate vaccines cover the greatest number of serogroups among available vaccines, and reductions in MenW IMD are already evident in the United Kingdom, where MenACWY vaccination has been incorporated into the immunization program [73]. As IMD occurs unpredictably, proactive vaccination strategies providing broad protection against disease-causing serogroups are advisable. MenACWY-TT, the most recently approved quadrivalent vaccine, administered as a primary infant series or as a single dose in toddlers and adolescents, provides broad seroprotection coupled with a favorable safety profile.

\section{ACKNOWLEDGEMENTS}

Funding. Sponsorship for this review and article processing charges were funded by Pfizer Inc. All authors had full access to all the data in this article and take complete responsibility for the integrity of the data and accuracy of the data analysis.

Medical Writing. Medical writing support was provided by Judith Kandel, PhD, of Complete Healthcare Communications, LLC (North Wales, PA, USA), a CHC Group Company, and was funded by Pfizer Inc.

Authorship. All named authors meet the International Committee of Medical Journal Editors (ICMJE) criteria for authorship for this article, take responsibility for the integrity of the work as a whole, and have given their approval for this version to be published.

Disclosures. Jessica Presa is an employee of Pfizer Inc and may hold stock/stock options. Jamie Findlow is an employee of Pfizer Inc and may hold stock/stock options. Jelena Vojicic is 
an employee of Pfizer Inc and may hold stock/stock options. Scott Williams is an employee of Pfizer Inc and may hold stock/ stock options. Lidia Serra is an employee of Pfizer Inc and may hold stock/stock options.

Compliance with Ethics Guidelines. This article is based on previously conducted studies and does not contain any studies with human participants or animals performed by any of the authors.

Data Availability. Data sharing is not applicable to this article as no datasets were generated or analyzed during the current study.

Open Access. This article is distributed under the terms of the Creative Commons Attribution-NonCommercial 4.0 International License (http://creativecommons.org/licenses/ by-nc/4.0/), which permits any noncommercial use, distribution, and reproduction in any medium, provided you give appropriate credit to the original author(s) and the source, provide a link to the Creative Commons license, and indicate if changes were made.

\section{REFERENCES}

1. Stephens DS. Biology and pathogenesis of the evolutionarily successful, obligate human bacterium Neisseria meningitidis. Vaccine. 2009;27:B71-7.

2. Centers for Disease Control and Prevention. Enhanced meningococcal disease surveillance report, 2016. https://www.cdc.gov/meningococcal/ downloads/NCIRD-EMS-Report.pdf. Accessed 3 June 2019.

3. European Centre for Disease Prevention and Control. Annual epidemiological report for 2015: invasive meningococcal disease. https://ecdc.europa.eu/ sites/portal/files/documents/AER_for_2015-mening ococcal-disease.pdf. Accessed 11 Oct 2018.

4. Dwilow R, Fanella S. Invasive meningococcal disease in the 21st century-an update for the clinician. Curr Neurol Neurosci Rep. 2015;15:2.

5. Bruce MG, Rosenstein NE, Capparella JM, et al. Risk factors for meningococcal disease in college students. JAMA. 2001;286:688-93.
6. MacLennan J, Kafatos G, Neal K, et al. Social behavior and meningococcal carriage in British teenagers. Emerg Infect Dis. 2006;12:950-7.

7. Mandal S, Campbell H, Ribeiro S, et al. Risk of invasive meningococcal disease in university students in England and optimal strategies for protection using MenACWY vaccine. Vaccine. 2017;35:5814-8.

8. Bassi C, Taha MK, Merle C, et al. A cluster of invasive meningococcal disease (IMD) caused by Neisseria meningitidis serogroup $\mathrm{W}$ among university students, France, February to May 2017. Euro Surveill. 2017;22:30574. https://doi.org/10.2807/15607917.ES.2017.22.28.30574.

9. Atkinson B, Gandhi A, Balmer P. History of meningococcal outbreaks in the United States: implications for vaccination and disease prevention. Pharmacotherapy. 2016;36:880-92.

10. University of Surrey. Meningitis Now: Public Health England (PHE) is working closely with Surrey County Council and NHS partners following three confirmed cases of meningitis among students at the University of Surrey. www.meningitisnow.org/ support-us/news-centre/news-stories/universitysurrey/. Accessed 3 June 2019.

11. Centers for Disease Control and Prevention. Meningococcal outbreaks. http://www.cdc.gov/ meningococcal/outbreaks/index.html. Accessed 3 June 2019.

12. Centers for Disease Control and Prevention. Chapter 14: Meningococcal disease. Public Health Foundation. https://www.cdc.gov/vaccines/pubs/pinkbo ok/downloads/mening.pdf. Accessed 3 June 2019.

13. Jafri RZ, Ali A, Messonnier NE, et al. Global epidemiology of invasive meningococcal disease. Popul Health Metr. 2013;11:11-7.

14. Harrison LH, Trotter CL, Ramsay ME. Global epidemiology of meningococcal disease. Vaccine. 2009;27(suppl 2):B51-63.

15. Menveo ${ }^{\circledR}$ (meningococcal [groups A, C, Y and W-135] oligosaccharide diphtheria $\mathrm{CRM}_{197}$ conjugate vaccine). Full Prescribing Information, GSK Vaccines S.r.l., Sovicille, Italy, 2017.

16. Menactra ${ }^{\circledR}$ (meningococcal [groups A, C, Y and W-135] polysaccharide diphtheria toxoid conjugate vaccine). Full Prescribing Information, Sanofi Pasteur Inc, Swiftwater, PA, 2016.

17. Nimenrix (meningococcal group A, C, W-135 and $\mathrm{Y}$ conjugate vaccine). Summary of Product Characteristics, Pfizer Manufacturing Belgium N.V., Belgium, 2017. 
18. Menjugate 10 micrograms suspension for injection (meningococcal group $\mathrm{C}$ conjugate vaccine). Summary of Product Characteristics, Novartis Vaccines and Diagnostics S.r.l., Sovicille, Italy, 2016.

19. NeisVac-C (meningococcal C conjugate vaccine). Full Prescribing Information, Pfizer, New York, NY, 2015.

20. World Health Organization. Meningococcal A conjugate vaccine: updated guidance, February 2015. Wkly Epidemiol Rec. 2015;90:57-68.

21. Menitorix (Haemophilus type b and meningococcal group $\mathrm{C}$ conjugate vaccine). Summary of Product Characteristics, GlaxoSmithKline, Middlesex, UK, 2016.

22. Maiden MC. The impact of protein-conjugate polysaccharide vaccines: an endgame for meningitis? Philos Trans R Soc Lond B. 2013;368:20120147.

23. Pelton SI. The global evolution of meningococcal epidemiology following the introduction of meningococcal vaccines. J Adolesc Health. 2016;59(suppl):S3-11.

24. Wyle FA, Artenstein MS, Brandt BL, et al. Immunologic response of man to group B meningococcal polysaccharide vaccines. J Infect Dis. 1972;126:514-21.

25. Bruge J, Bouveret-Le Cam N, Danve B, Rougon G, Schulz D. Clinical evaluation of a group B meningococcal $N$-propionylated polysaccharide conjugate vaccine in adult, male volunteers. Vaccine. 2004;22:1087-96.

26. Finne J, Leinonen M, Makela PH. Antigenic similarities between brain components and bacteria causing meningitis. Implications for vaccine development and pathogenesis. Lancet. 1983;2:355-7.

27. McNamara LA, Thomas JD, MacNeil J, et al. Meningococcal carriage following a vaccination campaign with MenB-4C and MenB-FHbp in response to a university serogroup $\mathrm{B}$ meningococcal disease outbreak-Oregon, 2015-2016. J Infect Dis. 2017;216:1130-40.

28. Bexsero (meningococcal group B vaccine). Full Prescribing Information, GlaxoSmithKline, Research Triangle Park, NC, 2017.

29. Hong E, Giuliani MM, Deghmane AE, et al. Could the multicomponent meningococcal serogroup B vaccine (4CMenB) control Neisseria meningitidis capsular group $\mathrm{X}$ outbreaks in Africa? Vaccine. 2013;31:1113-6.

30. Harris SL, Tan C, Andrew L, et al. The bivalent factor $\mathrm{H}$ binding protein meningococcal serogroup $\mathrm{B}$ vaccine elicits bactericidal antibodies against representative non-serogroup $B$ meningococci. Vaccine. 2018;36:6867-74.

31. Stefanelli P, Neri A, Vacca P, et al. Meningococci of serogroup X clonal complex 181 in refugee camps, Italy. Emerg Infect Dis. 2017;23:870-2.

32. Vuocolo S, Balmer P, Gruber WC, et al. Vaccination strategies for the prevention of meningococcal disease. Hum Vaccin Immunother. 2018;14:1203-15.

33. de Greeff SC, de Melker HE, Spanjaard L, Schouls LM, van Derende A. Protection from routine vaccination at the age of 14 months with meningococcal serogroup C conjugate vaccine in the Netherlands. Pediatr Infect Dis J. 2006;25:79-80.

34. Ramsay ME, Andrews NJ, Trotter CL, Kaczmarski EB, Miller E. Herd immunity from meningococcal serogroup C conjugate vaccination in England: database analysis. BMJ. 2003;326:365-6.

35. Lawrence GL, Wang H, Lahra M, Booy R, McIntyre $\mathrm{PB}$. Meningococcal disease epidemiology in Australia 10 years after implementation of a national conjugate meningococcal $\mathrm{C}$ immunization programme. Epidemiol Infect. 2016;144:2382-91.

36. Kristiansen PA, Ba AK, Ouedraogo AS, et al. Persistent low carriage of serogroup A Neisseria meningitidis two years after mass vaccination with the meningococcal conjugate vaccine. MenAfriVac. BMC Infect Dis. 2014;14:663.

37. Cohn AC, MacNeil JR, Clark TA, et al. Prevention and control of meningococcal disease: recommendations of the Advisory Committee on Immunization Practices (ACIP). MMWR Recomm Rep. 2013;62:1-28.

38. Ministers Department of Health. Quad-strain meningococcal vaccine to be added to National Immunisation Program. http://www.health.gov.au/ internet/ministers/publishing.nsf/Content/97678E E0888F2877CA258227007CCBFF/\$File/GH016.pdf. Accessed 3 June 2019.

39. Villena R, Santolaya ME. Chilean experience with serogroup W outbreak and meningococcal ACWY conjugate vaccines. Presented at: 14th Congress of the EMGM, European Meninogococcal and Haemophilus Disease Society, September 18-21, 2017; Prague, Czech Republic.

40. Ministerie van Volksgezondheid Welzijn en Sport. MenACWY-vaccin vervangt MenC-vaccin. https:// rijksvaccinatieprogramma.nl/nieuwsbrieven/april2018. Accessed 30 May 2019.

41. Public Health England. Invasive meningococcal disease in England: Annual report for 2017 to 2018 
supplementary data tables. https://assets.publis hing.service.gov.uk/government/uploads/system/up loads/attachment_data/file/752085/Laboratory_con firmed_cases_of_IMD_England_data_tables_2017to 2018.pdf. Accessed 18 July 2019.

42. Public Health England. Meningococcal ACWY conjugate vaccination (MenACWY). London, UK: National Health Service, England; June 22, 2015. https://assets.publishing.service.gov.uk/government /uploads/system/uploads/attachment_data/file/4379 01/150622_ACWY_bipartite_letter.pdf. Accessed 18 July 2019.

43. Hong E, Barret AS, Terrade A, et al. Clonal replacement and expansion among invasive meningococcal isolates of serogroup $\mathrm{W}$ in France. J Infect. 2018;76:149-58.

44. European Centre for Disease Prevention and Control. Surveillance atlas of infectious diseases. https:// ecdc.europa.eu/en/surveillance-atlas-infectiousdiseases. Accessed 3 June 2019.

45. European Centre for Disease Prevention and Control. Recommended immunisations for meningococcal disease. http://vaccine-schedule.ecdc.europa. eu/Pages/Scheduler.aspx. Accessed 3 June 2019.

46. Signorelli C, Guerra R, Siliquini R, Ricciardi W. Italy's response to vaccine hesitancy: an innovative and cost effective National Immunization Plan based on scientific evidence. Vaccine. 2017;35:4057-9.

47. National Institute for Public Health and the Environment, Ministry of Health, Welfare and Sport. Meningococcal disease in the Netherlands: background information for the Health Council. https:// www.rivm.nl/bibliotheek/rapporten/2017-0031. pdf. Accessed 3 June 2019.

48. Knol MJ, Ruijs WL, Antonise-Kamp L, de Melker HE, van der Ende A. Implementation of MenACWY vaccination because of ongoing increase in serogroup W invasive meningococcal disease, the Netherlands, 2018. Euro Surveill. https://doi.org/10. 2807/1560-7917.ES.2018.23.16.18-00158.

49. Lahra MM, Enriquez RP. Annual report of the Australian Meningococcal Surveillance Programme, 2011. http://www.health.gov.au/internet/main/ publishing.nsf/Content/cda-cdi3603-pdf-cnt.htm/ \$FILE/cdi3603c.pdf. Accessed 3 June 2019.

50. Lahra MM, Enriquez RP, for the National Neisseria Network. Australian Meningococcal Surveillance Programme annual report, 2015. http://www. health.gov.au/internet/main/publishing.nsf/conte nt/cda-cdi4004i.htm. Accessed 3 June 2019.

51. Australian Government Department of Health. Invasive meningococcal disease National
Surveillance Report with a focus on MenW. December 31, 2017. https://www1.health.gov.au/ internet/main/publishing.nsf/Content/5FEABC4B4 95BDEC1CA25807D001327FA/\$File/1Jan-31-Dec 2017-Consol-Invasive-Men-W.pdf. Accessed 18 July 2019.

52. Tsang R, Hoang L, Tyrrell G, et al. Increase in Neisseria meningitidis serogroup $\mathrm{W}$ invasive disease in Canada: 2009-2016. https://www.canada.ca/ content/dam/phac-aspc/migration/phac-aspc/publi cat/ccdr-rmtc/17vol43/dr-rm43-7-8/assets/pdf/17 vol43_7_8-eng.pdf\#page=4. Accessed 3 June 2019.

53. Li YA, Tsang R, Desai S, Dehhan H. Enhanced surveillance of invasive meningococcal disease in Canada, 2006-2011. Can Commun Dis Rep. 2014;40:160-9.

54. Public Health Agency of Canada. Vaccine Preventable Disease: Surveillance Report to December 31, 2015. https://www.canada.ca/en/publichealth/services/publications/healthy-living/vaccine -preventable-disease-surveillance-report-december31-2015.html. Accessed 3 June 2019.

55. Canadian Paediatric Society. Update on invasive meningococcal vaccination for Canadian children and youth. https://www.cps.ca/en/documents/positi on/invasive-meningococcal-vaccination. Accessed 3 June 2019.

56. BC Centre for Disease Control. History of Immunization in BC. http://www.bccdc.ca/resourcegallery/Documents/Guidelines\%20and\%20Forms/ Guidelines\%20and\%20Manuals/Epid/CD\%20Manu al/Chapter\%202\%20-\%20Imms/HistoryImmuniza tion.pdf. Accessed 3 June 2019.

57. Salvadori M, Bortolussi R. Meningococcal vaccines in Canada: an update. Paediatr Child Health. 2011;16:485-6.

58. Organización Panamericana de la Salud. Informe Regional de SIREVA II, 2006. http://www1.paho. org/spanish/AD/THS/EV/labs_Sireva_II_2006.pdf? $\mathrm{ua}=1$. Accessed 3 June 2019.

59. Organización Panamericana de la Salud. Informe Regional de SIREVA II, 2010. http://www.paho.org/ hq/index.php?option=com_content\&view=article \&id $=5536 \% 3$ A2011-sireva-ii\&catid=1591\%3Aabout \&Itemid=3966\&lang=pt. Accessed 17 July 2019.

60. Organización Panamericana de la Salud. Informe Regional de SIREVA II, 2014. http://iris.paho.org/ xmlui/bitstream/handle/123456789/33875/978927 5319420-spa.pdf?ua=1. Accessed 17 July 2019.

61. Ministerio de Salud (Republica Argentina). Fundamentos de la introducción de la vacuna tetravalente (ACYW) conjugada contra meningococo al 
Calendario Nacional de Inmunizaciones. http:// www.msal.gob.ar/images/stories/bes/graficos/00000 00927cnt-2016-12_lineamientos-meningo.pdf. Accessed 3 June 2019.

62. Ministerio de Salud (Republica Argentina). Calendario Nacional de Vacunación 2017. http://www. msal.gob.ar/index.php/programas-y-planes/184-cal endario-nacional-de-vacunacion-2016. Accessed 3 June 2019.

63. Ministerio de Salud (Gobierno de Chile). Informe de Resultados de Vigilancia de Laboratorio: Enfermedad Invasora Neisseria meningitidis 2017. http:// www.ispch.cl/sites/default/files/Informe\%20Neisser ia\%20meningitidis\%20\%20SE\%201-52\%202017\% 20v2.pdf. Accessed 3 June 2019.

64. Ministerio de Salud (Gobierno de Chile). Vaccination Calendar 2017. http://vacunas.minsal.cl/ calendario-de-vacunacion-2017/. Accessed 30 May 2019.

65. Ladhani SN, Ramsay M, Borrow R, et al. Enter B and $\mathrm{W}$ : two new meningococcal vaccine programmes launched. Arch Dis Child. 2016;101:91-5.

66. Stefanelli P, Miglietta A, Pezzotti P, et al. Increased incidence of invasive meningococcal disease of serogroup C/clonal complex 11, Tuscany, Italy, 2015 to 2016. Euro Surveill. 2016;21:30176. https:// doi.org/10.2807/1560-7917.ES.2016.21.12.30176.

67. Pezzotti P, Miglietta A, Neri A, et al. Meningococcal $C$ conjugate vaccine effectiveness before and during an outbreak of invasive meningococcal disease due to Neisseria meningitidis serogroup C/cc11, Tuscany, Italy. Vaccine. 2018;36:4222-7.

68. Australian Government Department of Health. National Immunisation Program Schedule. https:// beta.health.gov.au/health-topics/immunisation/im munisation-throughout-life/national-immunisati on-program-schedule. Accessed 3 June 2019.

69. Safadi MA, Berezin EN, Arlant LH. Meningococcal disease: epidemiology and early effects of immunization programs. J Pediatr Infect Dis Soc. 2014;3:91-3.

70. Ladhani SN, Beebeejaun K, Lucidarme J, et al. Increase in endemic Neisseria meningitidis capsular group W sequence type 11 complex associated with severe invasive disease in England and Wales. Clin Infect Dis. 2015;60:578-85.

71. Christensen H, May M, Bowen L, Hickman M, Trotter CL. Meningococcal carriage by age: a systematic review and meta-analysis. Lancet Infect Dis. 2010;10:853-61.
72. Public Health England. Laboratory confirmed cases of invasive meningococcal infection (England): October to December 2017. Health Protection Report. 2018;12:ePub.

73. Campbell H, Edelstein M, Andrews N, et al. Emergency meningococcal ACWY vaccination program for teenagers to control group W meningococcal disease, England, 2015-2016. Emerg Infect Dis. 2017;23:1184-7.

74. Ministère des Solidarités et de la Santé. Calendrier des vaccinations et recommandations vaccinales 2018. http://solidarites-sante.gouv.fr/IMG/pdf/ calendrier_vaccinations_2018.pdf. Accessed 3 June 2019.

75. Puglia Salute. Approvato il nuovo Calendario Vaccinale per la Vita 2017 della Regione Puglia. https:// www.sanita.puglia.it/archivio-news_det/-/journal_ content/56/20182/approvato-il-nuovo-calendariovaccinale-per-la-vita-2017-della-regione-puglia. Accessed 26 Feb 2019.

76. E-R Salute. Vaccinazioni per bambini e adolescenti. http://salute.regione.emilia-romagna.it/sanita-pubb lica/vaccinazioni/vaccinazioni-bambini-adolescen ti. Accessed 26 Feb 2019.

77. Regione del Veneto. Calendario vaccinale. https:// www.vaccinarsinveneto.org/vaccinazioni-veneto/ calendario-vaccinale.html. Accessed 26 Feb 2019.

78. Australian Government Department of Health. Meningococcal W disease. http://www.health.gov. $\mathrm{au} /$ internet/main/publishing.nsf/Content/ohp-men ingococcal-W.htm. Accessed 17 July 2019.

79. National Centre for Immunisation Research \& Surveillance. FactSheet: meningococcal vaccines. http://www.ncirs.edu.au/assets/provider_resources/ fact-sheets/meningococcal-vaccines-fact-sheet.pdf. Accessed 17 July 2019.

80. The Hon Greg Hunt MP. \$52 million to deliver free meningococcal vaccine to teenagers. http://www. health.gov.au/internet/ministers/publishing.nsf/Co ntent/health-mediarel-yr2018-hunt128.htm. Accessed 17 July 2019.

81. Public Health Agency of Canada. Canada's Provincial and Territorial Routine (and Catch-up) Vaccination Routine Schedule Programs for Infants and Children. https://www.canada.ca/content/dam/ phac-aspc/documents/services/provincial-territorial -immunization-information/childhood_\%20schedu le.pdf. Accessed 17 July 2019.

82. Interior Health Authority. Meningococcal disease outbreak ends. https://www.interiorhealth.ca/ YourEnvironment/CommunicableDiseaseControl/ MengingococcalDocs/QA-\%20Okanagan\%20meni 
ngococcal\%20outbreak\%20ends.pdf. Accessed 3 June 2019.

83. Abad R, Lopez EL, Debbag R, Vazquez JA. Serogroup $\mathrm{W}$ meningococcal disease: global spread and current affect on the Southern Cone in Latin America. Epidemiol Infect. 2014;142:2461-70.

84. Gentile A, Bakir J, Agosti MR, et al. Meningococcal disease in children in Argentina. A 3-year active sentinel hospital surveillance study. Pediatr Infect Dis J. 2017;36:296-300.

85. Rubilar PS, Barra GN, Gabastou JM, et al. Increase of Neisseria meningitidis W:cc11 invasive disease in Chile has no correlation with carriage in adolescents. PLoS ONE. 2018;13:e0193572.

86. Nimenrix ${ }^{\mathrm{TM}}$ (meningococcal polysaccharide groups A, C, W-135 and Y conjugate vaccine). Summary of Product Characteristics, Pfizer Australia Pty Ltd, West Ryde, Australia, 2018.

87. Crum-Cianflone N, Sullivan E. Meningococcal vaccinations. Infect Dis Ther. 2016;5:89-112.

88. Serra LC, York LJ, Balmer P, Webber C. Meningococcal group A, C, W, and Y tetanus toxoid conjugate vaccine: a review of clinical data in adolescents. J Adolesc Health. 2018;63:269-79.

89. Adis Insights (Springer). Drug profile: meningococcal vaccine groups A C Y W-135 conjugate-Sanofi Pasteur. https://adisinsight.springer.com/drugs/ 800013939. Accessed 3 June 2019.

90. Adis Insights (Springer). Drug profile: Meningococcal vaccine groups A C Y W-135 conjugate-Novartis. https://adisinsight.springer.com/drugs/ 800018218. Accessed 3 June 2019.

91. Sanofi Pasteur Limited. Product Monograph: Menactra $^{\circledR}$. https://pdf.hres.ca/dpd_pm/00042668.PDF. Accessed 3 June 2019.

92. European Medicines Agency. Annex I: Summary of product characteristics (Menveo). https://www. ema.europa.eu/documents/product-information/ menveo-epar-product-information_en.pdf. Accessed 3 June 2019.

93. National Centre for Immunisation Research \& Surveillance. Fact Sheet. Meningococcal vaccines for Australians: information for immunisation providers. http://www.ncirs.edu.au/assets/provider resources/fact-sheets/meningococcal-vaccines-factsheet.pdf. Accessed 17 July 2019.

94. Merino Arribas JM, Carmona Martinez A, Horn M, et al. Safety and immunogenicity of the quadrivalent meningococcal serogroups $\mathrm{A}, \mathrm{C}, \mathrm{W}$ and $\mathrm{Y}$ tetanus toxoid conjugate vaccine coadministered with routine childhood vaccines in European infants: an open, randomized trial. Pediatr Infect Dis J. 2017;36:e98-107.

95. Dbaibo G, Tinoco Favila JC, Traskine M, Jastorff A, Van der Wielen M. Immunogenicity and safety of MenACWY-TT, a meningococcal conjugate vaccine, co-administered with routine childhood vaccine in healthy infants: a phase III, randomized study. Vaccine. 2018;36:4102-11.

96. Vesikari T, Karvonen A, Bianco V, Van der Wielen $M$, Miller J. Tetravalent meningococcal serogroups A, C, W-135 and Y conjugate vaccine is well tolerated and immunogenic when co-administered with measles-mumps-rubella-varicella vaccine during the second year of life: an open, randomized controlled trial. Vaccine. 2011;29:4274-84.

97. Cutland CL, Nolan T, Halperin SA, et al. Immunogenicity and safety of one or two doses of the quadrivalent meningococcal vaccine MenACWY-TT given alone or with the 13-valent pneumococcal conjugate vaccine in toddlers: a phase III, open-label, randomised study. Vaccine. 2018;36:1908-16.

98. Vesikari T, Forsten A, Boutriau D, et al. A randomized study to assess the immunogenicity, antibody persistence and safety of a tetravalent meningococcal serogroups $\mathrm{A}, \mathrm{C}, \mathrm{W}-135$ and $\mathrm{Y}$ tetanus toxoid conjugate vaccine in children aged $2-10$ years. Hum Vaccin Immunother. 2012;8:1882-91.

99. Vesikari T, Forsten A, Bianco V, Van der Wielen M, Miller JM. Antibody persistence up to 5 years after vaccination of toddlers and children between 12 months and 10 years of age with a quadrivalent meningococcal ACWY-tetanus toxoid conjugate vaccine. Hum Vaccin Immunother. 2016;12:132-9.

100. Ishola DA, Andrews N, Waight $\mathrm{P}$, et al. Randomized trial to compare the immunogenicity and safety of a CRM or TT conjugated quadrivalent meningococcal vaccine in teenagers who received a CRM or TT conjugated serogroup $\mathrm{C}$ vaccine at preschool age. Pediatr Infect Dis J. 2015;34:865-74.

101. van Ravenhorst MB, van der Klis FRM, van Rooijen DM, Sanders EAM, Berbers GAM. Adolescent meningococcal serogroup $\mathrm{A}, \mathrm{W}$ and $\mathrm{Y}$ immune responses following immunization with quadrivalent meningococcal $\mathrm{A}, \mathrm{C}, \mathrm{W}$ and $\mathrm{Y}$ conjugate vaccine: optimal age for vaccination. Vaccine. 2017;35:4753-60.

102. van Ravenhorst MB, van der Klis FRM, van Rooijen $\mathrm{DM}$, et al. Meningococcal serogroup C immunogenicity, antibody persistence and memory B-cells induced by the monovalent meningococcal serogroup $C$ versus quadrivalent meningococcal serogroup ACWY conjugate booster vaccine: a randomized controlled trial. Vaccine. 2017;35:4745-52. 
103. Halperin SA, Baine Y, Domachowske JB, et al. Comparison of the safety and immunogenicity of a novel quadrivalent meningococcal ACWY-tetanus toxoid conjugate vaccine and a marketed quadrivalent meningococcal ACWY-diphtheria toxoid conjugate vaccine in healthy individuals 10-25 years of age. J Pediatr Infect Dis Soc. 2014;3:33-42.

104. Borja-Tabora CF, Montalban C, Memish ZA, et al. Long-term immunogenicity and safety after a single dose of the quadrivalent meningococcal serogroups A, C, W, and Y tetanus toxoid conjugate vaccine in adolescents and adults: 5-year follow-up of an open, randomized trial. BMC Infect Dis. 2015;15:409.

105. Baxter R, Baine Y, Kolhe D, et al. Five-year antibody persistence and booster response to a single dose of meningococcal $\mathrm{A}, \mathrm{C}, \mathrm{W}$ and $\mathrm{Y}$ tetanus toxoid conjugate vaccine in adolescents and young adults: an open, randomized trial. Pediatr Infect Dis J. 2015;34:1236-43.

106. Rivera L, Schwarz TF, Kim KH, et al. Immunogenicity and safety of the quadrivalent meningococcal vaccine MenACWY-TT co-administered with a combined diphtheria-tetanus-acellular pertussis vaccine versus their separate administration in adolescents and young adults: a phase III, randomized study. Vaccine. 2018;36:4750-8.

107. Rivera L, Chanthavanich P, Poder A, et al. MenACWY-TT is immunogenic when co-administered with Tdap and AS04-HPV16/18 in girls and young women: results from a phase III randomized trial. Vaccine. 2018;36:3967-75.

108. Guthmann J, Fonteneau L, Levy-Bruhl D. Assessment of vaccination coverage in France: current sources and data. Saint-Maurice: Institut de Veille Sanitaire, 2012. https://www.santepubliquefrance. $\mathrm{fr} /$ recherche/\#search=Assessment $\% 20$ of\%20vaccina tion $\% 20$ coverage $\% 20 \mathrm{in} \% 20$ France:\%20current $\%$ 20sources\%20and\%20data. Accessed 18 July 2019.

109. Buscail C, Gagniere B. Vaccination coverage of adolescents: results of a Defense and Citizenship Day-based survey. Med Mal Infect. 2016;46:25-31.

110. National Center for Immunization and Respiratory Diseases. General recommendations on immunization-recommendations of the Advisory Committee on Immunization Practices (ACIP). MMWR Recomm Rep. 2011;60:1-64.

111. Stokley S, Jeyarajah J, Yankey D, et al. Human papillomavirus vaccination coverage among adolescents, 2007-2013, and postlicensure vaccine safety monitoring, 2006-2014-United States. MMWR Morb Mortal Wkly Rep. 2014;63:620-4.

112. Boostrix (tetanus toxoid, reduced diphtheria toxoid and acellular pertussis vaccine, adsorbed). Full
Prescribing Information, GlaxoSmithKline, Research Triangle Park, NC, 2016.

113. Messonier N, Centers for Disease Control and Prevention. Dear Pharmacist letter. https://media. pharmacist.com/documents/Dear_Pharmacist_lett er_9-2016.pdf. Accessed 3 June 2019.

114. Booy R, Gentile A, Nissen M, Whelan J, Abitbol V. Recent changes in the epidemiology of Neisseria meningitidis serogroup $\mathrm{W}$ across the world, current vaccination policy choices and possible future strategies. Hum Vaccin Immunother. 2018;15: 470-80.

115. Schurink-van 't Klooster T, de Melker H. The National Immunisation Programme in the Netherlands: surveillance and developments in 2016-2017. https://www.rivm.nl/publicaties/natio nal-immunisation-programme-in-netherlands-surv eillance-and-developments-in-2016. Accessed 18 July 2019.

116. Institute of Medicine, National Academy of Sciences, Chap 11. Meningococcal vaccine. https:// www.nap.edu/read/13164/chapter/13\#611. Accessed 17 July 2019.

117. Office Fédéral de la Santé Publique. Protection contre les maladies invasives à méningocoques: adaptation des recommandations de vaccination. https://www.infovac.ch/docs/public/neisseria/prot ection-contre-les-maladies-invasives-a-meningocoq ues-adaptation-des-recommandations-de-vaccinati on.pdf. Accessed 3 June 2019.

118. Abdelhameed AS, Morris GA, Adams GG, et al. An asymmetric and slightly dimerized structure for the tetanus toxoid protein used in glycoconjugate vaccines. Carbohydr Polym. 2012;90:1831-5.

119. Borrow R, Andrews N, Findlow H, et al. Kinetics of antibody persistence following administration of a combination meningococcal serogroup $\mathrm{C}$ and Haemophilus influenzae type $\mathrm{b}$ conjugate vaccine in healthy infants in the United Kingdom primed with a monovalent meningococcal serogroup $C$ vaccine. Clin Vaccine Immunol. 2010;17:154-9.

120. Southern J, Borrow R, Andrews N, et al. Immunogenicity of a reduced schedule of meningococcal group C conjugate vaccine given concomitantly with the Prevenar and Pediacel vaccines in healthy infants in the United Kingdom. Clin Vaccine Immunol. 2009;16:194-9.

121. Vipond C, Care R, Feavers IM. History of meningococcal vaccines and their serological correlates of protection. Vaccine. 2012;30:B10-7.

122. Block SL, Szenborn L, Daly W, et al. A comparative evaluation of two investigational meningococcal 
ABCWY vaccine formulations: results of a phase 2 randomized, controlled trial. Vaccine. 2015;33:2500-10.

123. Saez-Llorens X, Aguilera Vaca DC, Abarca K, et al. Immunogenicity and safety of investigational vaccine formulations against meningococcal serogroups A, B, C, W, and Y in healthy adolescents. Hum Vaccin Immunother. 2015;11:1507-17.

124. Szenborn L, Block SL, Jackowska T, et al. Immune responses to booster vaccination with meningococcal $A B C W Y$ vaccine after primary vaccination with either investigational or licensed vaccines: a phase 2 randomized study. Pediatr Infect Dis J. 2018;37:475-82.

125. ClinicalTrials.gov. A Trial to Describe the Immunogenicity and Safety of 2 Doses of Bivalent rLP2086 (Trumenba) and a pentavalent meningococcal vaccine in healthy subjects $\geq 10$ to $<26$ years of age. https://clinicaltrials.gov/ct2/show/ NCT03135834?term=trumenba\&rank=8. Accessed 30 May 2019.

126. Ladhani SN, Giuliani MM, Biolchi A, et al. Effectiveness of meningococcal B vaccine against endemic hypervirulent Neisseria meningitidis W strain, England. Emerg Infect Dis. 2016;22:309-11.

127. Read RC, Baxter D, Chadwick DR, et al. Effect of a quadrivalent meningococcal ACWY glycoconjugate or a serogroup $\mathrm{B}$ meningococcal vaccine on meningococcal carriage: an observer-blind, phase 3 randomised clinical trial. Lancet. 2014;384:2123-31.

128. Government of Manitoba. Meningococcal conjugate quadrivalent (Men-C-ACYW-135) vaccine public health-factsheet. https://www.gov.mb.ca/ health/publichealth/factsheets/mcqv.pdf. Accessed 3 June 2019. 